\title{
Nickel nanoparticles decorated on electrospun polycaprolactone/chitosan nanofibers as flexible, highly active and reusable nanocatalyst in the reduction of nitrophenols under mild conditions
}

\author{
Kadir Karakas a , Asli Celebioglu ${ }^{\mathrm{b}}$, Metin Celebi $^{\mathrm{a}}$, Tamer Uyar ${ }^{\mathrm{b}, \mathrm{c}, * *, 2}$, \\ Mehmet Zahmakiran ${ }^{\mathrm{a}, *, 1}$ \\ a Nanomaterials and Catalysis (NanoMatCat) Research Laboratory, Department of Chemistry, Yüzüncü Yıl University, Van, 65080, Turkey \\ b UNAM-National Nanotechnology Research Center, Bilkent University, Ankara, 06800, Turkey \\ ' Institute of Materials Science E Nanotechnology, Bilkent University, Ankara, 06800, Turkey
}

\section{A R T I C L E I N F O}

\section{Article history:}

Received 3 July 2016

Received in revised form 2 October 2016

Accepted 8 October 2016

Available online 13 October 2016

\section{Keywords:}

Electrospinning

Nanofibers

Nickel

Nitrophenols

Reduction

Nanocatalyst

\begin{abstract}
A B S T R A C T
Today, the reduction of nitro aromatics stands a major challenge because of the pollutant and detrimental nature of these compounds. In the present study, we show that nickel( 0 ) nanoparticles (Ni-NP) decorated on electrospun polymeric (polycaprolactone(PCL)/chitosan) nanofibers (Ni-NP/ENF) effectively catalyze the reduction of various nitrophenols (2-nitrophenol, 2,4-dinitrophenol, 2,4,6-trinitrophenol) under mild conditions. Ni-NP/ENF nanocatalyst was reproducibly prepared by deposition-reduction technique. The detailed characterization of these Ni-NP/ENF based nanocatalyst have been performed by using various spectroscopic tools including ICP-OES, P-XRD, XPS, SEM, BFTEM, HRTEM and BFTEM-EDX techniques. The results revealed the formation of well-dispersed nickel $(0) \mathrm{NP}\left(d_{\text {mean }}=2.71-2.93 \mathrm{~nm}\right)$ on the surface of electrospun polymeric nanofibers. The catalytic activity of the resulting Ni-NP/ENF was evaluated in the catalytic reduction of nitrophenols in aqueous solution in the presence of sodium borohydride $\left(\mathrm{NaBH}_{4}\right)$ as reducing agent, in which Ni-NP/ENF nanocatalyst has shown high activity (TOF $=46.2 \mathrm{~mol}$ 2-nitrophenol/mol Ni min; $48.2 \mathrm{~mol}$ 2,4-dinitrophenol/mol Ni min; $65.6 \mathrm{~mol}$ 2,4,6-trinitrophenol/mol Ni min). More importantly, due to the nanofibrous polymeric support, Ni-NP/ENF has shown a flexible characteristics along with reusability property. Testing the catalytic stability of Ni-NP/ENF revealed that this new catalytic material provides high reusability performance (at 3rd reuse $86 \%$ for 2-nitrophenol, $83 \%$ 2,4-dinitrophenol and $82 \%$ 2,4,6-trinitrophenol) for the reduction of nitrophenols even at room temperature and under air. The present study reported here also includes the compilation of wealthy kinetic data for Ni-NP/ENF catalyzed the reduction of nitrophenols in aqueous sodium borohydride solution depending on temperature and type of support material $\left(\mathrm{Al}_{2} \mathrm{O}_{3}, \mathrm{C}, \mathrm{SiO}_{2}\right)$ to understand the effect of the support material and determine the activation parameters.
\end{abstract}

(C) 2016 Elsevier B.V. All rights reserved.

\section{Introduction}

Nitrophenols are a kind of the most widely used industrial nitro aromatic compounds (NAC's) and frequently employed as interme-

\footnotetext{
* Corresponding author.

** Corresponding author at: UNAM-National Nanotechnology Research Center, Bilkent University, Ankara, 06800, Turkey.

E-mail addresses: tamer@unam.bilkent.edu.tr (T. Uyar), zmehmet@yyu.edu.tr (M. Zahmakiran).

1 Website: www.nanomatcat.com.

2 Website: http://unam.bilkent.edu.tr/ uyar.
}

diates in the production of explosives, pharmaceuticals, pesticides, pigments, dye, wood preservatives and rubber chemicals $[1,2]$. Although, they are useful intermediates in the fabrication of various aforementioned materials, they also act as common environmental pollutants because of their toxicity and resistance to microbial degradation [3,4]. For these reasons, nitrophenols are considered as a priority pollutant by the Environmental Protection Agency (EPA) of USA, and its concentration in natural waters is restricted to less than $10 \mathrm{mg} / \mathrm{L}[5,6]$. Up to date, various techniques such as membrane filtration $[7,8]$, microbial degradation $[9,10]$, photocatalytic degradation [11,12], electro-Fenton method [13,14], electrocoagulation $[15,16]$, adsorption $[17,18]$, electrochemical treatment 
$[19,20]$ and chemical reduction [21,22] have been reported for removing nitrophenols from contaminated water. Among these techniques, the chemical reduction of nitrophenols seems to be most efficient way to remove nitrophenols from waste contaminated water. Additionally, aminophenols formed via the reduction of nitrophenols usually find applications as a photographic developer of films, corrosion inhibitor, drying agent, precursor for the manufacture of analgesic and antipyretic drugs [23-25].

Over the last decade, nanotechnology, which deal primarily with the synthesis, characterization, and exploration of nanomaterials, has became a popular research area, where significant efforts have been made to use nanoscale systems [26]. The impact of these researches to both fundamental science and potential applications has been tremendous and is still growing [27]. Nanomaterials have already found many fascinating applications in a wide variety field of chemistry, physics, electronics, biology, medicine and catalysis. The latter application field of nanomaterials is of particular interest as it is the key for the development of starting chemicals, fine chemicals and pharmaceutical drugs from raw materials [28]. Compared to their bulk-counterparts, metal nanoparticles have much higher surface-to-volume ratio, thus, larger fraction of catalytically active atoms on the surface, and these surface atoms of nanoparticles do not order themselves in the same way as those in bulk metal [29]. Furthermore, the electrons in nanoparticles are confined to spaces that can be as small as a few atoms widths across giving rise to quantum size effects [30] and higher Fermi potential which leads to the lowering of reduction potential value, and hence metal nanoparticles can function as a catalyst for many electron-transfer reactions such as reduction of nitrophenols [31].

Hitherto, various types of ligands or surfactants stabilized $\mathrm{Au}$ [32], Ag [33], Pd [34], Pt [34,35] and Ni [36] nanoparticles have already been tested as active nanocatalyst in the reduction of nitrophenols in the presence of sodium borohydride as a reductant. However, the recovery of noble metal nanoparticles from such stabilizers-containing systems is not easy and also makes UV/vis spectroscopy monitoring of the reaction extremely difficult due to the presence of suspended nanoparticles in the reaction solution. In addition, there is another critical matter to obtain pure active metal surfaces by staying away from surface contamination resulting from surface protecting groups, which often lead to a decrease in the catalytic performance resulting from the blocking of active sites. Moreover, the low stability of these colloidal nanoparticles against agglomeration diminishes their reusability performances, which is one of the most important criterias in the heterogeneous catalysis. In this context, the generation of the metal nanoparticles on solid support materials has already been acknowledged for preventing aggregation of active metal nanoparticles and providing high reusability performances in the nitrophenols reduction [37-40]. Additionally, the use of supported metal nanoparticles as nanocatalyst in the reduction of nitrophenols may provide a kinetic control of the catalytic reaction, whereas it is almost impossible in the catalytic employment of colloidal metal nanoparticles. Despite all the advancement in supported metal nanocatalyst preparation [41], there is still great interest in developing catalyst supports with high stability and large surface area. At this concern, electrospinning has been considered as one of the powerful methods to generate nanofibrous support materials with a huge specific surface area [42-45]. Recent studies have already shown that electrospun polymeric nanofibers act as efficient support material in the stabilization of $\mathrm{Fe}(0)$ [46], $\mathrm{Au}(0)$ [47], $\mathrm{Pd}(0)$ [48], $\mathrm{Pt}(0)$ [49] and $\mathrm{Ag}(0)$ [50] nanoparticles for environmental remediation applications [46-51]. The catalytic stability results obtained in these studies prompted us to use electrospun polymeric nanofibers as catalyst support for guest catalytically active metal nanoparticles in the catalytic reduction of nitrophenols.
In this study, we report a facile synthesis of nickel nanoparticles (Ni-NP) decorated on electrospun polymeric (polycaprolactone (PCL)/chitosan) nanofibers, hereafter referred to as $\mathrm{Ni}-\mathrm{NP} / \mathrm{ENF}$, and their excellent catalysis for the reduction of various nitrophenols including 2-nitrophenol, 2,4-dinitrophenol, 2,4,6-trinitrophenol in aqueous sodium borohydride $\left(\mathrm{NaBH}_{4}\right.$; as reducing agent) solution. Chitosan subunit has been selected in the preparation of electrospun polymeric nanofibers because of its $-\mathrm{NH}_{2}$ groups, which may act as ligand stabilizer to surface bound Ni-NP. Some of us have already reported that the existence of surface grafted $-\mathrm{NH}_{2}$ groups on solid support materials can act as stabilizing agents to supported PdAuCr [52], PdAg- $\mathrm{MnO}_{\mathrm{x}}$ [53],

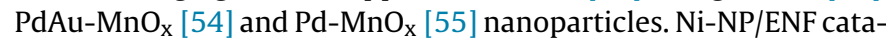
lyst was simply and reproducibly prepared through surfactant-free deposition-in-situ reduction technique [56] at room temperature, and characterized by inductively coupled plasma-optical emission spectroscopy (ICP-OES), powder X-ray diffraction (P$\mathrm{XRD}$ ), X-ray photoelectron spectroscopy (XPS), scanning electron microscopy (SEM), bright field transmission electron microscopy (BFTEM) and high resolution transmission electron microscopy (HR-TEM). The sum of their results revealed that the formation of nickel $(0)$ nanoparticles $\left(d_{\text {mean }}=2.71-2.93 \mathrm{~nm}\right.$ ) on the surface of electrospun PCL/chitosan nanofibers. These Ni-NP/ENF catalyst provide exceptional activities (TOF $=46.2 \mathrm{~mol} 2$-nitrophenol $/ \mathrm{mol}$ Ni min; $48.2 \mathrm{~mol}$ 2,4-dinitrophenol/mol Ni min; $65.6 \mathrm{~mol}$ 2,4,6trinitrophenol/mol $\mathrm{Ni} \mathrm{min}$ ) in the reduction of nitrophenols even at room temperature and under air. Moreover, the excellent durability of Ni-NP/ENF and their flexibile nature enable them reusable nanocatalyst for the nitrophenols reduction.

\section{Experimental}

\subsection{Materials}

Nickel(II) chloride hexahydrate $\left(\mathrm{NiCl}_{2} \cdot 6 \mathrm{H}_{2} \mathrm{O}\right)$, methanol $\left(\mathrm{CH}_{3} \mathrm{OH}\right)$, sodium borohydride $\left(\mathrm{NaBH}_{4}\right)$, 2-nitrophenol $\left(\mathrm{O}_{2} \mathrm{NC}_{6} \mathrm{H}_{4} \mathrm{OH}\right), \quad 2,4$-dinitrophenol $\quad\left(\left(\mathrm{O}_{2} \mathrm{~N}\right)_{2} \mathrm{C}_{6} \mathrm{H}_{3} \mathrm{OH}\right), \quad 2,4,6$ trinitrophenol (picric acid; $\left(\mathrm{O}_{2} \mathrm{~N}\right)_{3} \mathrm{C}_{6} \mathrm{H}_{2} \mathrm{OH}$ ), acetic acid (AA; $\left.\mathrm{CH}_{3} \mathrm{CO}_{2} \mathrm{H}\right)$, formic acid (FA; $\left.\mathrm{HCOOH}\right)$, polycaprolactone $\left(\left(\mathrm{C}_{6} \mathrm{H}_{10} \mathrm{O}_{2}\right)_{\mathrm{n}}\right.$ PCL, Mw: 80,000 g/mol) and chitosan (Poly(Dglucosamine), low molecular weight) were purchased from Sigma-Aldrich ${ }^{\circledR}$ and used without any purification. Deionized water was distilled by water purification system (Milli-Q Water Purification System). All glassware and Teflon-coated magnetic stir bars were washed with acetone and copiously rinsed with distilled water before drying in an oven at $323 \mathrm{~K}$.

\subsection{Characterization}

Nickel contents of the Ni-NP/ENF, Ni/C, Ni/SiO ${ }_{2}$ and $\mathrm{Ni} / \mathrm{Al}_{2} \mathrm{O}_{3}$ samples were determined by ICP-OES (Leeman, Direct Reading Echelle) after each sample was completely dissolved in a mixture of $\mathrm{HNO}_{3} / \mathrm{HCl}(1 / 3$ ratio). The scanning electron microscope (SEM) (Quanta 200 FEG, FEI) was used for the morphological characterizations of nanofibers. Prior to imaging, samples were sputtered with $5 \mathrm{~nm} \mathrm{Au} / \mathrm{Pd}$ (PECS-682) and the average fiber diameter (AFD) was calculated from the SEM images by analyzing at least 100 fibers. During the SEM characterization, energy dispersive X-ray (EDX) measurements were also performed for the elemental analysis of the nanofibers. Bright field transmission electron microscopy (BFTEM) and high resolution transmission electron microscopy (HR-TEM) were performed on FEI-Tecnai G2F30, operating at $300 \mathrm{kV}$. For imaging of TEM, electrospinning of nanofibers was performed directly onto the TEM grids. Then, the nanofibers collected onto TEM grids were exposed to treatment for the grow- 
ing of Ni-NP and imaging was performed thereafter. The chemical composition of nanofibers was investigated by X-ray photoelectron spectrometer (XPS) (Thermo Fisher Scientific). XPS was used by means of a flood gun charge neutralizer system equipped with a monochromated $\mathrm{Al} \mathrm{K \alpha} \mathrm{X}$-ray source $(\mathrm{h} v=1486.6 \mathrm{eV})$. The pass energy, step size, and spot size were $30 \mathrm{eV}, 0.1 \mathrm{eV}$, and $400 \mathrm{~mm}$, respectively. In order to obtained detailed information, the high resolution spectra were recorded for the spectral regions relating to $\mathrm{Ni}, \mathrm{O}, \mathrm{C}$ and $\mathrm{N}$ at pass energy of $50 \mathrm{eV}$.

\subsection{Preparation of electrospun $P C L /$ chitosan nanofibers}

The bead-free and uniform PCL/chitosan nanofibers were produced by using binary solvent system; AA/FA. The homogenous electrospinning solutions were prepared by dissolving PCL and chitosan in AA/FA $(1 / 1(\mathrm{v} / \mathrm{v}))$ solvent mixture at $6.5 \%(\mathrm{w} / \mathrm{v})$ and $2 \%$ $(\mathrm{w} / \mathrm{v})$ polymer concentration, respectively. Afterwards, these clear solutions were loaded in $3 \mathrm{~mL}$ syringe fitted with a metallic needle of $0.4 \mathrm{~mm}$ inner diameter and they were located horizontally on a syringe pump (model KDS-101, KD Scientific, USA). One of the electrodes of high-voltage power supply (Spellman, SL30, USA) was clamped to the metallic needle and the plate aluminum collector was grounded. Electrospinning parameters were arranged as follows: feed rate of solutions $=0.5 \mathrm{~mL} / \mathrm{h}$, applied voltage $=15 \mathrm{kV}$, tip-to-collector distance $=10 \mathrm{~cm}$. The grounded stationary metal collector covered with an aluminum foil was used to deposit the electrospun nanofibers. The electrospinning apparatus was enclosed in a Plexiglas box and electrospinning was carried out at about $23{ }^{\circ} \mathrm{C}$ at $20 \%$ relative humidity. The collected nanofibers were dried over night at room temperature in a fume hood.

\subsection{In-situ formation of nickel nanoparticles decorated on electrospun polycaprolactone/chitosan nanofibers (Ni-NP/ENF) and their catalysis in the reduction of nitrophenols}

$\mathrm{Ni}-\mathrm{NP} / \mathrm{ENF}$ nanocatalyst was obtained by the conventional impregnation and subsequent reduction steps [56]. Typically, $2.0 \mathrm{~mL}$ methanol solution containing $\mathrm{NiCl}_{2} \cdot 6 \mathrm{H}_{2} \mathrm{O}(4.75 \mathrm{mg}$, $19.9 \mu \mathrm{mol} \mathrm{Ni}$ ) and ENF (3.0 mg) is mixed for $3 \mathrm{~h}$. Then, methanol was removed from the mixture by applying low vacuum $\left(10^{-1}\right.$ Torr $)$ at room temperature; the resulting solid was removed, washed with water $(3 \times 20 \mathrm{~mL})$ and dried in vacuum-oven at $303 \mathrm{~K}$ $\left(10^{-1}\right.$ Torr). An aqueous solution of nitrophenol $(2.0 \mathrm{mM} ; 20 \mu \mathrm{mol}$ nitrophenol corresponds to $2.78 \mathrm{mg}$ for $\mathrm{O}_{2} \mathrm{NC}_{6} \mathrm{H}_{4} \mathrm{OH}, 3.68 \mathrm{mg}$ for $\left(\mathrm{O}_{2} \mathrm{~N}\right)_{2} \mathrm{C}_{6} \mathrm{H}_{3} \mathrm{OH}$ and $4.58 \mathrm{mg}$ for $\left(\mathrm{O}_{2} \mathrm{~N}\right)_{3} \mathrm{C}_{6} \mathrm{H}_{2} \mathrm{OH}$ in $10.0 \mathrm{~mL} \mathrm{H}_{2} \mathrm{O}$, which were done in separate experiments), and $2.0 \mathrm{mg} \mathrm{Ni(II)/ENF}$ were taken in a jacketed one necked reaction flask $(20.0 \mathrm{~mL})$ containing a Teflon-coated stir bar was placed on a magnetic stirrer (Heidolph MR-3004) and thermostated to $298 \mathrm{~K}$ by using a constant temperature bath (Lab Companion RW-0525). Then, the mixture was stirred for $15 \mathrm{~min}$ to achieve thermal equilibrium. Next, $1.0 \mathrm{~mL}$ aqueous solution of sodium borohydride $(0.2 \mathrm{mmol}$ $\mathrm{NaBH}_{4}$ corresponds to $77.2 \mathrm{mg} \mathrm{NaBH}$ ) was added into the reaction flask and the catalytic reaction was started $(t=0 \mathrm{~min})$ by stirring the mixture at $>600 \mathrm{rpm}$. At each predetermined time interval $100 \mu \mathrm{L}$ of the reaction solution was withdrawn and diluted to $2.0 \mathrm{~mL}$ for the analysis of transformation efficiency of nitrophenol using a Shimadzu UV-3600 UV-vis spectrometer. The optical absorption spectra were measured at fixed wavelengths 416 , 359 and $393 \mathrm{~nm}$, which are the characteristic absorption peaks for 2-nitrophenol, 2.4-dinitrophenol and 2,4,6-trinitrophenol, respectively. The concentration of nitrophenol was calculated using a calibration curve constructed with absorbance of standard solutions. The extent of catalytic reduction was expressed as conversion, which was calculated as Eq. (1) shows;

conversion $=\mathrm{A} / \mathrm{A}_{0}$

where $A_{0}$ is the initial concentration and $A$ is the concentration of nitrophenol at certain time point.

\subsection{Reusability performance of Ni-NP/ENF in the catalytic reduction of nitrophenols}

After one complete reaction cycle, Ni-NP/ENF was isolated by suction filtration using Whatmann filter paper and washed with excess ethanol-water mixture and dried in vacuum-oven at $303 \mathrm{~K}$ $\left(10^{-1}\right.$ Torr $)$. Then, the dried catalyst weighed and used for the next cycle of catalytic reaction with fresh substrates.

\subsection{Determination of activation parameters for $\mathrm{Ni}-\mathrm{NP} / \mathrm{ENF}$ catalyzed reduction of nitrophenols}

In order to determine the activation parameters (Ea, $\Delta \mathrm{H}^{*}$ and $\Delta \mathrm{S}^{*}$ ) for the Ni-NP/ENF ( $2 \mathrm{mg} ; 0.9 \%$ wt Ni corresponds to $0.31 \mu \mathrm{mol}$ $\mathrm{Ni})$ catalyzed reduction of nitrophenols $(2.0 \mathrm{mM} ; 20 \mu \mathrm{mol}$ nitrophenol corresponds to $2.78 \mathrm{mg}$ for $\mathrm{O}_{2} \mathrm{NC}_{6} \mathrm{H}_{4} \mathrm{OH}, 3.68 \mathrm{mg}$ for $\left(\mathrm{O}_{2} \mathrm{~N}\right)_{2} \mathrm{C}_{6} \mathrm{H}_{3} \mathrm{OH}$ and $4.58 \mathrm{mg}$ for $\left(\mathrm{O}_{2} \mathrm{~N}\right)_{3} \mathrm{C}_{6} \mathrm{H}_{2} \mathrm{OH}$ in $10.0 \mathrm{~mL} \mathrm{H}_{2} \mathrm{O}$, which were done in separate experiments), the catalytic reaction was performed at different temperatures in the range of $298 \mathrm{~K}-318 \mathrm{~K}$ and the initial rate constants were determined and used to construct Arrhenius and Eyring-Polonyi plots to find activation parameters.

\subsection{Preparation of nickel nanoparticles supported on carbon $(\mathrm{Ni} / \mathrm{C})$, alumina $\left(\mathrm{Ni} / \mathrm{Al}_{2} \mathrm{O}_{3}\right)$ and silica $\left(\mathrm{Ni} / \mathrm{SiO}_{2}\right)$ catalysts}

In a three separate experiments $5.0 \mathrm{~mL}$ aqueous solution containing $\mathrm{NiCl}_{2} .6 \mathrm{H}_{2} \mathrm{O}(6.2 \mathrm{mg}, 25.9 \mu \mathrm{mol} \mathrm{Ni})$ and solid support ( $100 \mathrm{mg} \mathrm{C}, \mathrm{Al}_{2} \mathrm{O}_{3}, \mathrm{SiO}_{2}$ ) is mixed for $3 \mathrm{~h}$. After that, the fresh aqueous $\mathrm{NaBH}_{4}$ solution $(1.0 \mathrm{~mL}, 14 \mathrm{mg}, 0.38 \mathrm{mmol}$ ) was added to these mixtures and the resulting solutions were stirred for half an hour under ambient conditions. After centrifugation (6000 rpm, $5 \mathrm{~min}$ ), copious washing with water $(3 \times 20 \mathrm{~mL})$, filtration, and drying in oven at $373 \mathrm{~K}, \mathrm{Ni} / \mathrm{C}, \mathrm{Ni} / \mathrm{Al}_{2} \mathrm{O}_{3}$ and $\mathrm{Ni} / \mathrm{SiO}_{2}$ catalysts were obtained as powders.

\subsection{The uniqueness of Ni-NP/ENF nanocatalyst in the catalytic reduction of nitrophenols}

To investigate the uniqueness of $\mathrm{Ni}-\mathrm{NP} / \mathrm{ENF}$ with respect to $\mathrm{Ni} / \mathrm{C}, \mathrm{Ni} / \mathrm{Al}_{2} \mathrm{O}_{3}$ and $\mathrm{Ni} / \mathrm{SiO}_{2}$ catalysts; the catalytic reductions of 2-nitrophenol, 2.4-dinitrophenol and 2,4,6-trinitrophenol, respectively performed in a set of experiments under identical conditions $\left(0.31 \mu \mathrm{mol} \mathrm{Ni}\right.$ and $20 \mu \mathrm{mol}$ nitrophenol) by using $\mathrm{Ni} / \mathrm{C}, \mathrm{Ni} / \mathrm{Al}_{2} \mathrm{O}_{3}$ and $\mathrm{Ni} / \mathrm{SiO}_{2}$ catalysts in the presence of $0.2 \mathrm{mmol} \mathrm{NaBH}_{4}$ at $298 \mathrm{~K}$.

\section{Results and discussion}

\subsection{Preparation and characterization of $N i-N P / E N F$}

The bead-free and uniform $\mathrm{PCL} /$ chitosan polymeric nanofibers were fabricated by using electrospinning technique (Scheme 1). The morphology of the as-prepared electrospun PCL/chitosan nanofibers was investigated by SEM and the collected SEM images in different magnifications were given in Fig. $1(\mathrm{a}-\mathrm{c})$. These images indicative of the formation of smooth and uniform fibrous structure with a mean fiber diameter of $95 \pm 45 \mathrm{~nm}$ (Fig. 1(d)). Nickel nanoparticles supported on PCL/chitosan nanofibers (Ni-NP/ENF) 


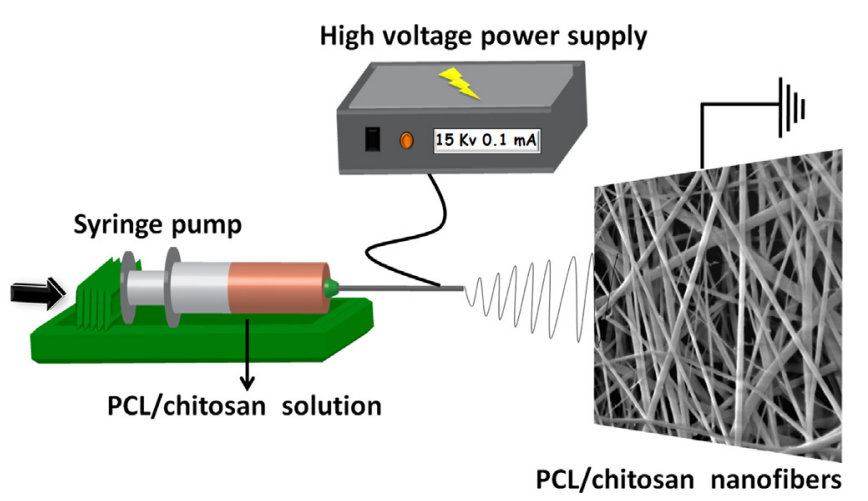

Scheme 1. Schematic illustration for the fabrication of PCL/chitosan nanofibers by electrospinning.

were obtained by the conventional impregnation and subsequent reduction technique [56]. For this purpose, firstly we prepared $\mathrm{Ni}(\mathrm{II}) /$ ENF precatalyst by the wet-impregnation of $\mathrm{NiCl}_{2} \cdot 6 \mathrm{H}_{2} \mathrm{O}$ precursor onto the surface of $\mathrm{PCL} /$ chitosan nanofibers at room temperature.

The white color of PCL/chitosan nanofibrous web was turn into green at the end of the surface deposition of $\mathrm{Ni}(\mathrm{II})$ and the amount of $\mathrm{Ni}(\mathrm{II})$ loading was found to be $0.9 \%$ wt by ICP-OES analysis. The formation of Ni-NP on the surface of PCL/chitosan nanofibers and the concomitant reduction of nitrophenols (2-nitrophenol, 2,4-dinitrophenol and 2,4,6-trinitrophenol) were done under insitu conditions by using sodium borohydride as reducing agent (Scheme 2).

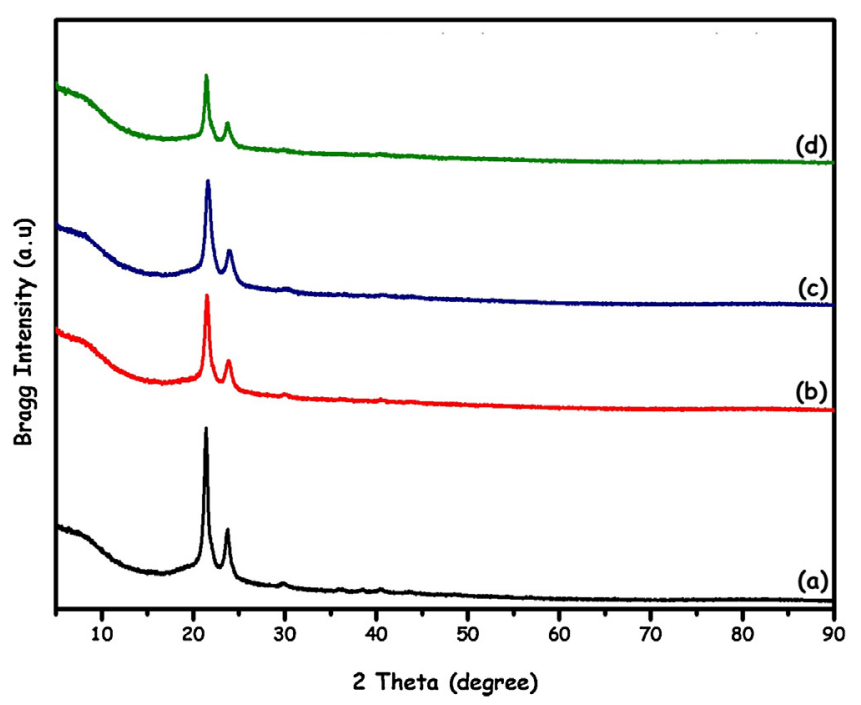

Fig. 2. P-XRD patterns of (a) PCL/chitosan nanofiber and Ni-NP/ENF samples obtained under in-situ conditions from the reductions of (b) 2-nitrophenol, (c) 2,4dinitrophenol and (d) 2,4,6-trinitrophenol in the $2 \theta$ range of 5-90.

Fig. 2 depicts P-XRD patterns of PCL/chitosan nanofibers in addition to those of Ni-NP/ENF samples obtained under in-situ conditions from the reductions of 2-nitrophenol, 2,4-dinitrophenol and 2,4,6-trinitrophenol. The PCL/chitosan nanofibers exhibited two strong diffraction peaks at Bragg angles $2 \theta=21.3^{\circ}$ and $23.9^{\circ}$, which represent the (110) and (200) reflections respectively of a polyethylene-like crystal structure of PCL polymer with
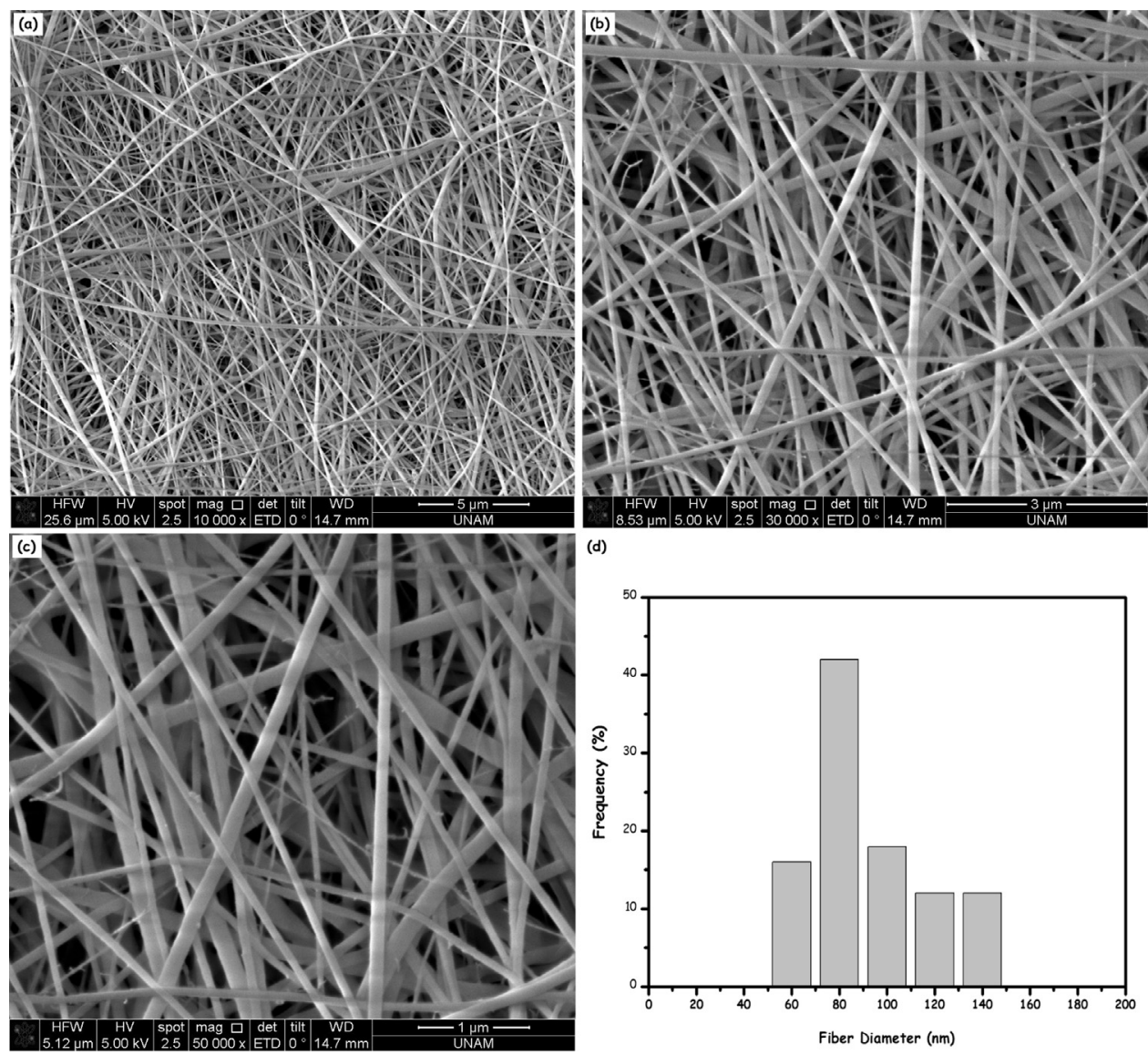

(d)

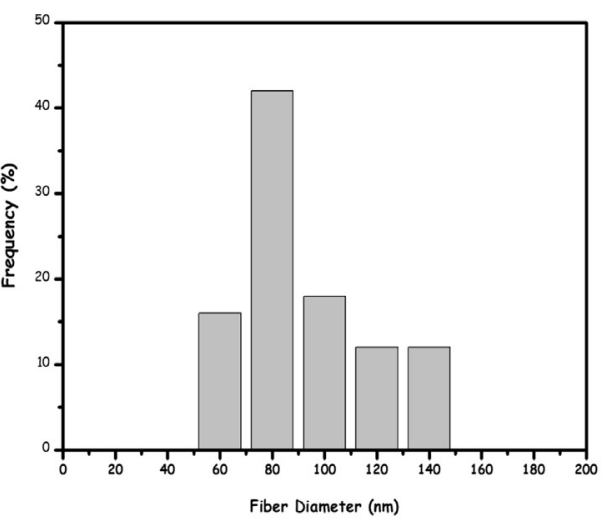

Fig. 1. SEM images of PCL/chitosan nanofibers at different magnifications (a-c) and (d) their fiber diameter distribution histogram. 


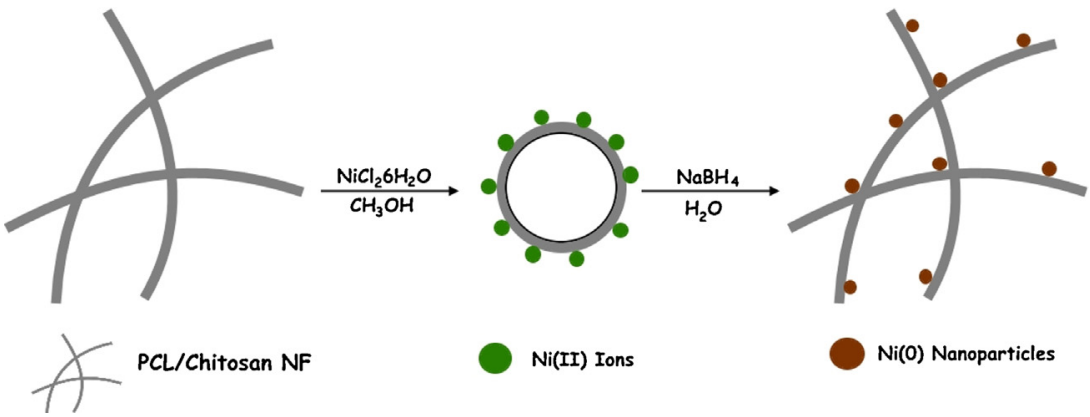

Scheme 2. Schematic illustration for the preparation of Ni-NP on the surface of electropun PCL/chitosan nanofibers.
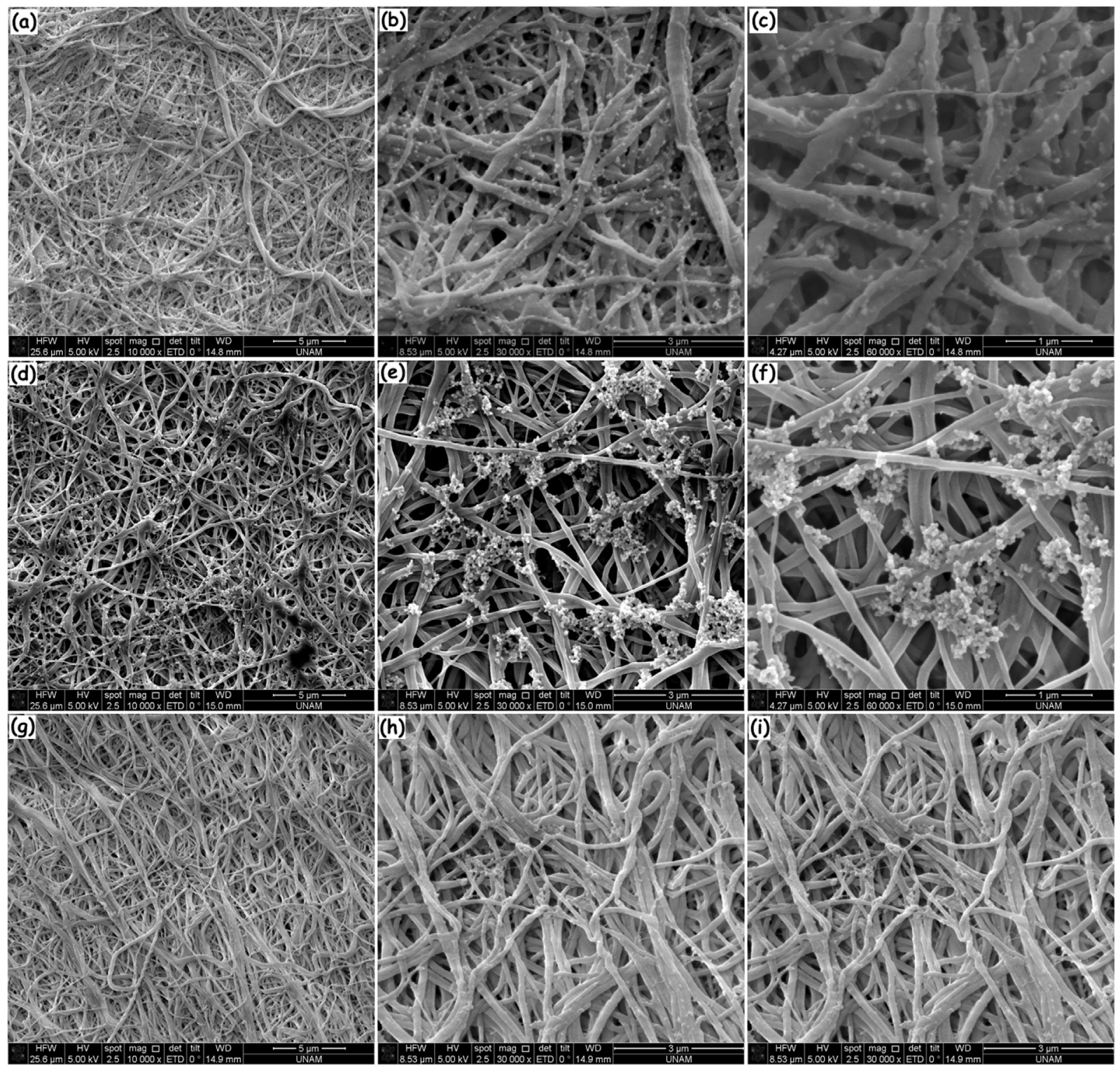

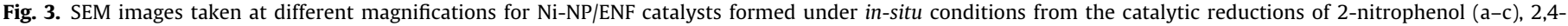
dinitrophenol (d-f) and 2,4,6-trinitrophenol (g-i) in aqueous $\mathrm{NaBH}_{4}$ solution at room temperature under air.

orthorhombic unit cell parameters $[57,58]$. P-XRD patterns of $\mathrm{Ni}$ $\mathrm{NP} / \mathrm{ENF}$ samples did not show $\mathrm{Ni}(0)$ phases due to the low $\mathrm{Ni}$ loading on PCL/chitosan nanofibers $(<5.0 \% \mathrm{wt})$, their P-XRD patterns are similar to that of the PCL/chitosan nanofibrous support, thus indicating that no new phases appear after the formation of
Ni-NP/ENF and that, after reaction, no observable alterations for the $\mathrm{PCL} /$ chitosan nanofibrous support is detected $[59,60]$.

The preservation of the nanofibrous structure of $\mathrm{PCL} / \mathrm{chitosan}$ web at the end of the Ni-NP/ENF formation was also confirmed by SEM analyses. Fig. 3 shows SEM images of Ni-NP/ENF sam- 

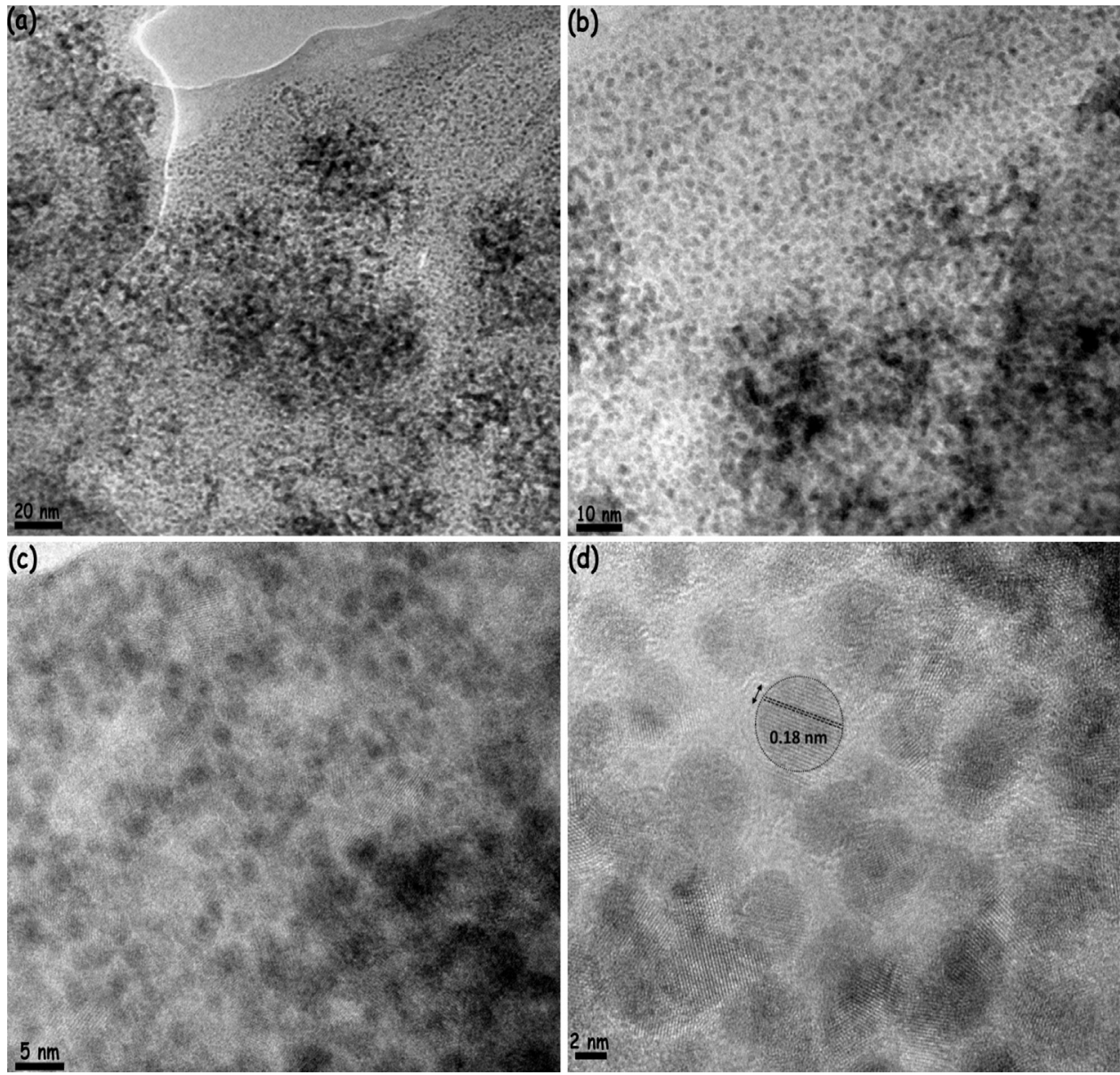

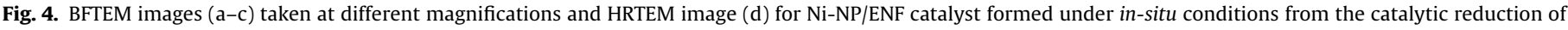
2,4-dinitrophenol in aqueous $\mathrm{NaBH}_{4}$ solution at room temperature under air.

ples formed under in-situ conditions from the reductions of 2-nitrophenol, 2,4-dinitrophenol and 2,4,6-trinitrophenol at different magnifications. The inspection of these images reveals that the preservation of fibrous structure and formation of clumped Ni-NP on the surface of PCL/chitosan nanofibers. Although, SEM images indicated that the formation of clumped Ni particles on the surface of PCL/chitosan nanofibers, BFTEM analyses reveals that the presence of surface supported Ni-NP. Fig. 4(a-c) shows the representative BFTEM images of Ni/ENF sample formed under in-situ conditions from the reduction of 2,4-dinitrophenol (see Fig. 10 (vide infra) Fig. S1 and for BFTEM images of samples formed under in-situ conditions from the reductions of 2-nitrophenol and 2,4-dinitrophenol, respectively), whose SEM images displayed the existence of some clumped particles. These BFTEM images taken at different magnifications clearly show the formation of welldispersed, small sized $\left(d_{\text {mean }}=2.79 \mathrm{~nm}\right)$ Ni NPs on the surface of $\mathrm{PCL} /$ chitosan nanofibers. EDX analysis performed during the BFTEM observation of Ni-NP/ENF from many different areas confirmed the presence of nickel metal in the analyzed regions (Fig. S2 in the Supporting information). The crystallinity of these in-situ generated Ni-NP on the surface of $\mathrm{PCL} /$ chitosan nanofibers was also analyzed by HRTEM and the collected HRTEM image of Ni-NP/ENF sample formed under in-situ conditions from the reduction of 2,4-dinitrophenol was given in Fig. 4(d). This HRTEM image is displaying the highly crystalline nature of the Ni-NP and the crystalline fringe distance of $0.18 \mathrm{~nm}$ was measured for the individual Ni-NP, which can be assigned to [200] $d$ spacing of fcc Ni-NP [61]. In order to determine the chemical environment the chemical environment and the oxidation state of nickel in the Ni-NP/ENF samples, we per- formed survey and Ni 2p core level XPS measurements (Fig. 5). Fig. 5(a) shows the survey XPS spectrum of that reveals the existence of $\mathrm{Ni}$ in addition to the $\mathrm{PCL} /$ chitosan nanofibers elements $(\mathrm{C}$, $\mathrm{N}$ and $\mathrm{O}$ ). The inspection of $\mathrm{Ni} 2 \mathrm{p}$ core level XPS spectrum given in Fig. 6(b) gives three peaks centered around 856, 862 and $878 \mathrm{eV}$, which can readily be assigned to $\mathrm{Ni}(0) 3 \mathrm{p}_{3 / 2}, \mathrm{Ni}(\mathrm{II}) 2 \mathrm{p}_{3 / 2}$ and $\mathrm{Ni}(0)$ $2 \mathrm{p}_{1 / 2}$, respectively [62]. The peaks observed for $\mathrm{Ni}(\mathrm{II}) 2 \mathrm{p}_{3 / 2}$ show the presence of $\mathrm{NiO}$, that may originate from the surface oxidation of $\mathrm{Ni}(0)$ nanoparticles during the XPS sampling procedure [63]. Additionally, the slight shifts towards higher energy region observed in the sequence of the samples recovered from the reduction of 2-nitrophenol $\rightarrow$ 2,4-dinitrophenol $\rightarrow$ 2,4,6-trinitrophenol can be explained by the interaction of nickel $(0)$ nanoparticles with formed $-\mathrm{NH}_{2}$ groups, which is expected to induce a positive charge on the surface metal and that would increase the binding energies of $\mathrm{Ni}(0) 3 \mathrm{p}_{3 / 2}$ and $\mathrm{Ni}(0) 2 \mathrm{p}_{1 / 2}$.

\subsection{The catalytic activity of Ni-NP/ENF in the reduction of 2-nitrophenol, 2,4-dinitrophenol and 2,4,6-trinitrophenol in the presence of $\mathrm{NaBH}_{4}$}

The catalytic reduction of toxic nitrophenols to the corresponding aminophenol derivatives by sodium borohydride $\left(\mathrm{NaBH}_{4}\right)$ in the presence of Ni-NP/ENF catalyst was selected as a model test reaction to examine the catalytic performance of Ni-NP/ENF catalyst. In alkaline solution nitrophenols show their strongest absorption bands at $415 \mathrm{~nm}$ (2-nitrophenol), $359 \mathrm{~nm}$ (2,4-dinitrophenol), $393 \mathrm{~nm}$ (2,4,6-trinitrophenol). Thus, by tracing and monitoring the change of the absorption peak, the relative kinetic parameters can 


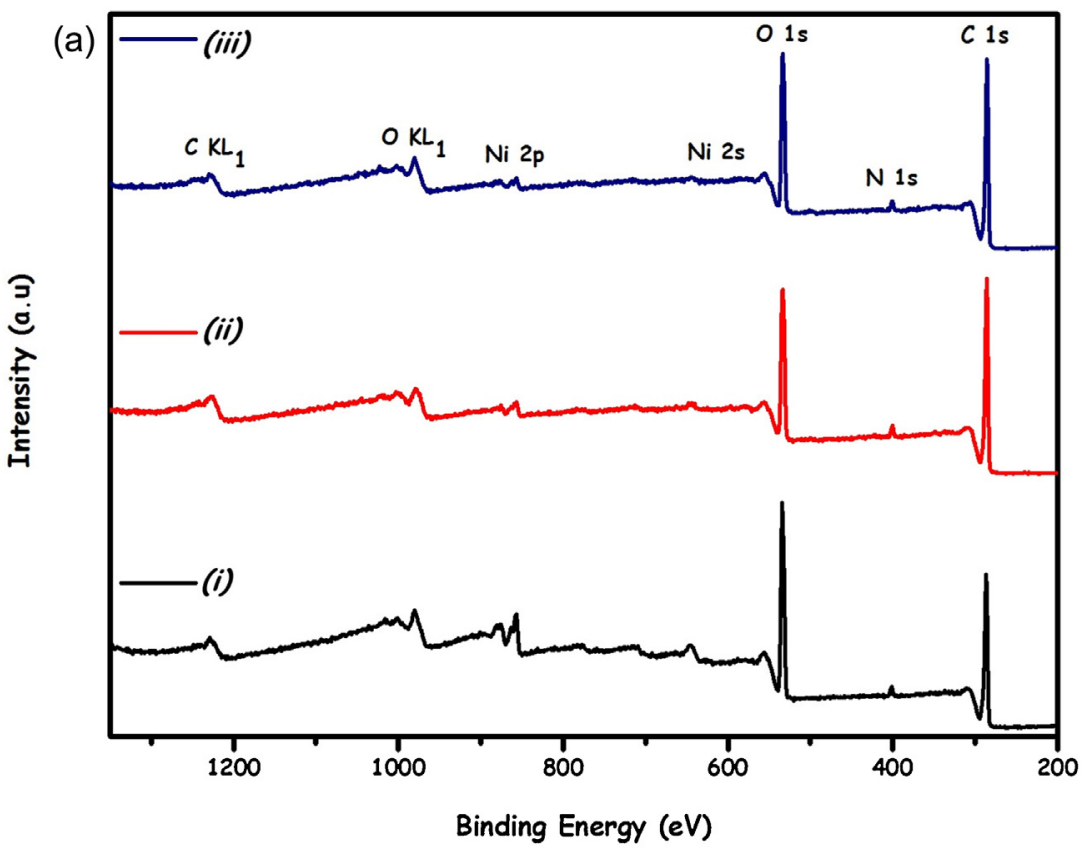

(b)

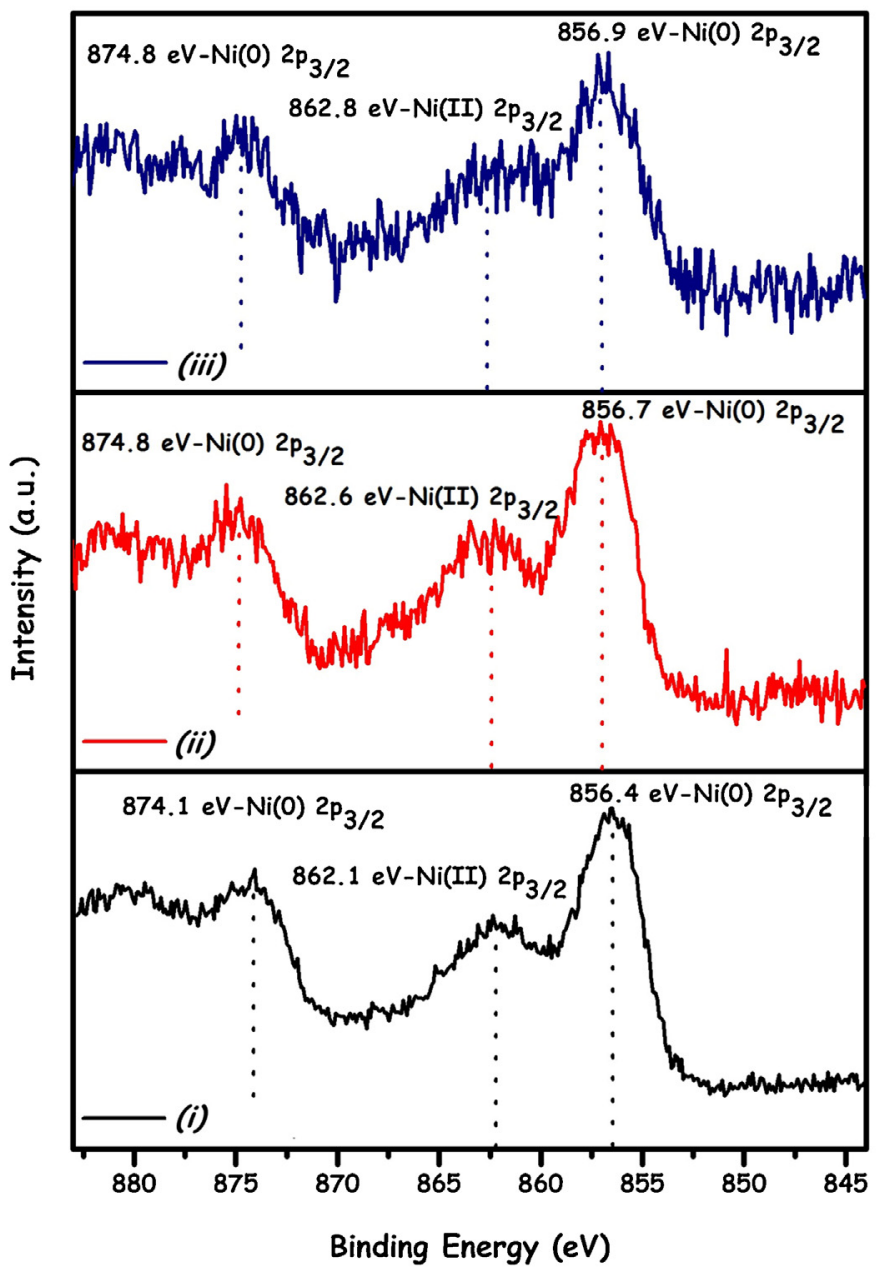

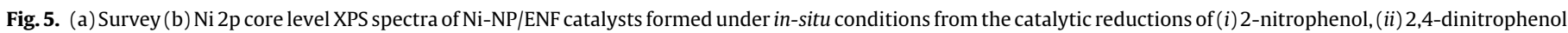
and (iii) 2,4,6-trinitrophenol in aqueous $\mathrm{NaBH}_{4}$ solution at room temperature.

be obtained. Before testing the catalytic activity of Ni-NP/ENF one has to check whether (i) self-hydrolysis of sodium borohydride $\left(\mathrm{NaBH}_{4}\right)$ reduces the nitrophenols and (ii) the support material
$\mathrm{PCL} /$ chitosan catalyzes the reduction of nitrophenols. For that reason, we performed six control experiments in which the reductions of 2-nitrophenol, 2,4-dinitrophenol and 2,4,6-trinitrophenol 
Table 1

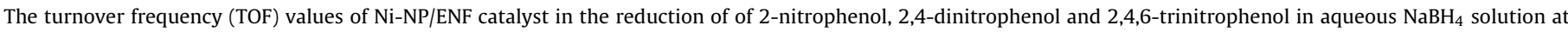
different temperatures.

\begin{tabular}{|c|c|c|c|c|}
\hline Substrate & $298 \mathrm{~K} \mathrm{TOF}\left(\mathrm{min}^{-1}\right)$ & $303 \mathrm{~K} \mathrm{TOF}\left(\mathrm{min}^{-1}\right)$ & $308 \mathrm{~K} \mathrm{TOF}\left(\mathrm{min}^{-1}\right)$ & $313 \mathrm{~K} \mathrm{TOF}\left(\mathrm{min}^{-1}\right)$ \\
\hline 2-Nitrophenol & 46.2 & 61.2 & 71.6 & 117.2 \\
\hline 2,4-Dinitrophenol & 48.2 & 54.9 & 65.5 & 181.2 \\
\hline 2, 4, 6-Trinitrophenol & 65.6 & 75.7 & 93.6 & 160.9 \\
\hline
\end{tabular}
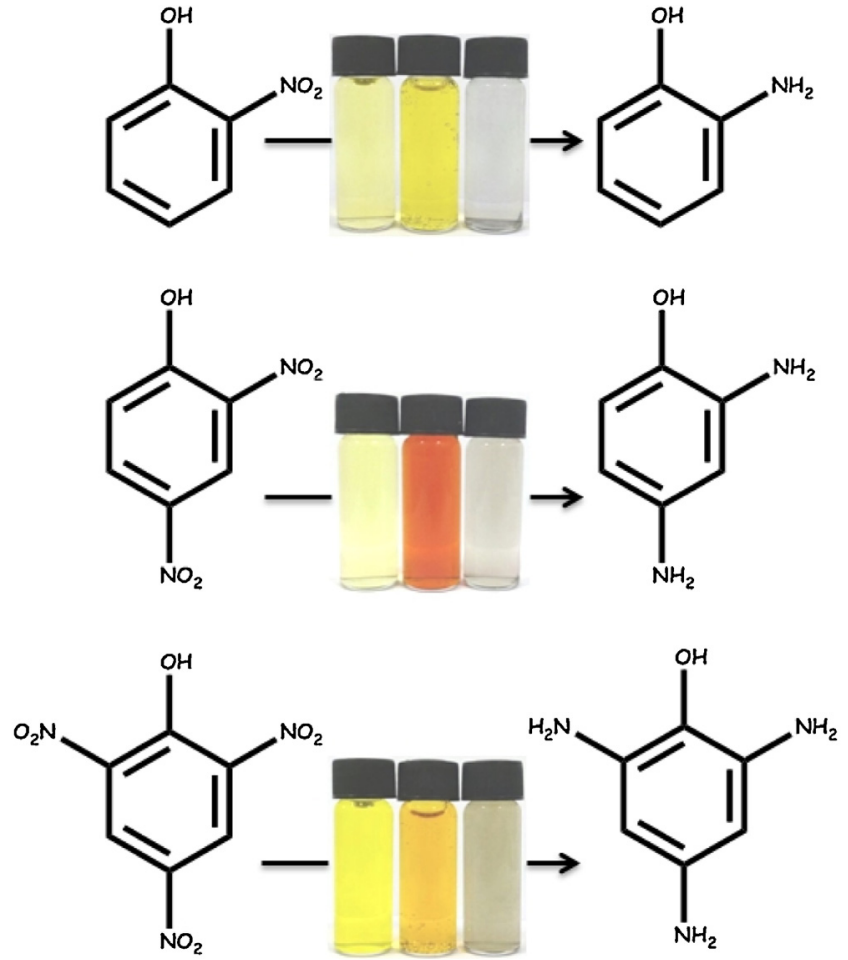

Scheme 3. The change in the color of the solution through the Ni-NP/ENF catalyzed reduction of 2-nitrophenol, 2,4-dinitrophenol and 2,4,6-trinitrophenol.

were investigated in the presence of $\mathrm{NaBH}_{4}$ and $\mathrm{PCL} /$ chitosan nanofibers $+\mathrm{NaBH}_{4}$. We found that the completely identical results for $\mathrm{NaBH}_{4}$ assisted reduction of nitrophenols in the absence and presence of $\mathrm{PCL} /$ chitosan nanofibers (Fig. S3 in the Supporting information) and these results indicated that $\mathrm{PCL} / \mathrm{chitosan}$ nanofibers are catalytically inactive in the reduction of nitrophenols. In the absence of Ni-NF/ENF catalyst the consumption rate of nitrophenols in the presence of equivalent amounts of $\mathrm{NaBH}_{4}$ was found to be 2,4,6-trinitrophenol $(55 \mathrm{~min})>2,4$-dinitrophenol $(65 \mathrm{~min})>2$ nitrophenol (240 min), these results revealed that the consumption of nitrophenols occurs very slowly by the self-hydrolysis of sodium borohydride (Eq. (1)).

$\mathrm{NaBH}_{4}+2 \mathrm{H}_{2} \mathrm{O} \rightarrow \mathrm{NaBO}_{2}+4 \mathrm{H}_{2}$

However, in the presence of very low amount of $\mathrm{Ni}(\mathrm{II})$ impregnated on the surface of $\mathrm{PCL} /$ chitosan nanofibers $(\mathrm{Ni}=0.31 \mu \mathrm{mol})$ the in-situ formation of Ni-NP/ENF and concomitant reduction of nitrophenols occur rapidly at $298 \mathrm{~K}$ (Fig. 6). The color of the reaction solutions changed from yellow to colorless, gray or light brown depending on the substrate throughout the Ni-NP/ENF catalyzed reduction of nitrophenols (Scheme 3 ).

The reduction of nitrophenols in the presence of catalysts with an excess $\mathrm{NaBH}_{4}$ proceeds via the formation of phenolate ions by the addition of $\mathrm{NaBH}_{4}$ and the transformation of phenolate ions to aminophenols [46-51]. The absorption bands of 2-nitrophenol, 2,4-dinitrophenol and 2,4,6-trinitrophenol at 415, 359 and $393 \mathrm{~nm}$, respectively shifted to 283, 448 and $306 \mathrm{~nm}$ upon
Table 2

Activation parameters for the Ni-NP/ENF catalyzed reduction of 2-nitrophenol, 2, 4-dinitrophenol and 2, 4, 6-trinitrophenol in aqueous $\mathrm{NaBH}_{4}$ solution.

\begin{tabular}{llll}
\hline Substrate & $\mathrm{E}_{\mathrm{a}}\left(\mathrm{kJ} \mathrm{mol}^{-1}\right)$ & $\Delta \mathrm{H}^{\#}\left(\mathrm{~kJ} \mathrm{~mol}^{-1}\right)$ & $\Delta \mathrm{S}^{\#}\left(\mathrm{~J} \mathrm{~mol}^{-1} \mathrm{~K}^{-1}\right)$ \\
\hline 2-Nitrophenol & 45.6 & 43.1 & -103.4 \\
2, 4-Dinitrophenol & 63.9 & 61.3 & -43.1 \\
2, 4, 6-Trinitrophenol & 44.8 & 42.3 & -103.6 \\
\hline
\end{tabular}

the addition of fresh $\mathrm{NaBH}_{4}$ solution. This indicates the formation of 2-nitrophenolate, 2,4-dinitrophenolate and 2,4,6-trinitophenolate in the reaction solution and the intensities of their absorption bands gradually decreased as the reduction proceeds in the presence of $\mathrm{Ni}$ NP/ENF catalyst (Fig. 6(a-c)). The consideration of the conversion graphs given in Fig. 6(d) reveals that (i) the complete consumption of nitrophenols occurred within $3 \mathrm{~min}$, and (ii) the initial rate of Ni-NP/ENF catalyzed reduction of nitrophenols at the same temperature $(298 \mathrm{~K})$ and nickel concentration $(0.31 \mu \mathrm{mol})$ followed the order of 2,4,6-trinitrophenol >2,4-dinitrophenol > 2-nitrophenol. The initial turnover frequency (TOF) of Ni-NP/ENF catalyst in the catalytic reduction of 2-nitrophenol, 2,4-dinitrophenol and 2,4,6-trinitrophenol were found to be $46.2 \mathrm{~mol} 2$-nitrophenol $/ \mathrm{mol}$ $\mathrm{Ni}$ min, $48.2 \mathrm{~mol}$ 2,4-dinitrophenol/mol $\mathrm{Nimin}, 65.6 \mathrm{~mol}$ 2,4,6trinitrophenol $/ \mathrm{mol} \mathrm{Nimin.} \mathrm{It} \mathrm{should} \mathrm{be} \mathrm{noted} \mathrm{that,} \mathrm{these} \mathrm{TOF}$ values recorded at room temperature are higher than those found with r-GO supported $\mathrm{Cu}_{2} \mathrm{O}$ nanoparticles [64], polyaniline coated Au nanorods [65], hydrogel supported $\mathrm{Ni}$ nanoparticles [66] and hydrogel supported Co nanoparticles [67] catalyst for the catalytic reduction of the same substrates.

\subsection{The activation parameters for Ni-NP/ENF catalyzed reduction of 2-nitrophenol, 2,4-dinitrophenol and 2,4,6-trinitrophenol}

The effect of temperature on the Ni-NP/ENF catalyzed reduction of 2-nitrophenol, 2,4-dinitrophenol and 2,4,6-trinitrophenol was also investigated by performing a series of experiments for $\mathrm{Ni}$-NP/ENF catalyzed reduction of 2-nitrophenol, 2,4-dinitrophenol and 2,4,6-trinitrophenol at 298, 303, 308 and $313 \mathrm{~K}$ (Fig. 7). Expectedly (Fig. 7(a-c)), the catalytic activity of Ni-NP/ENF enhanced by the increase of the temperature in the reduction of all nitrophenol substrates and the determined TOF values at different temperatures were given in Table 1 . The observed rate constants $\left(\mathrm{k}_{\mathrm{obs}}\right)$ at each temperature were calculated from the linear portion of each plot and these rate constants were used to construct Arrhenius and Eyring-Polonyi plots given in Fig. 8 to find the activation energy $\left(E_{a}\right)$, activation enthalpy $\left(\Delta H^{\#}\right)$ and activation entropy $\left(\Delta S^{\#}\right)$. The determined $\mathrm{E}_{\mathrm{a}}, \Delta \mathrm{H}^{\#}$ and $\Delta \mathrm{S}^{\#}$ values were tabulated in Table 2. Assuming that the apparent activation parameters calculated from the macroscopic kinetic data given above are relevant to the most critical activation step in nitrophenols reduction mechanism, one can argue that the positive magnitude of the apparent activation enthalpy and large negative value of the apparent activation entropy imply the presence of an associative reaction step revealing a transition state $[68,69]$. 

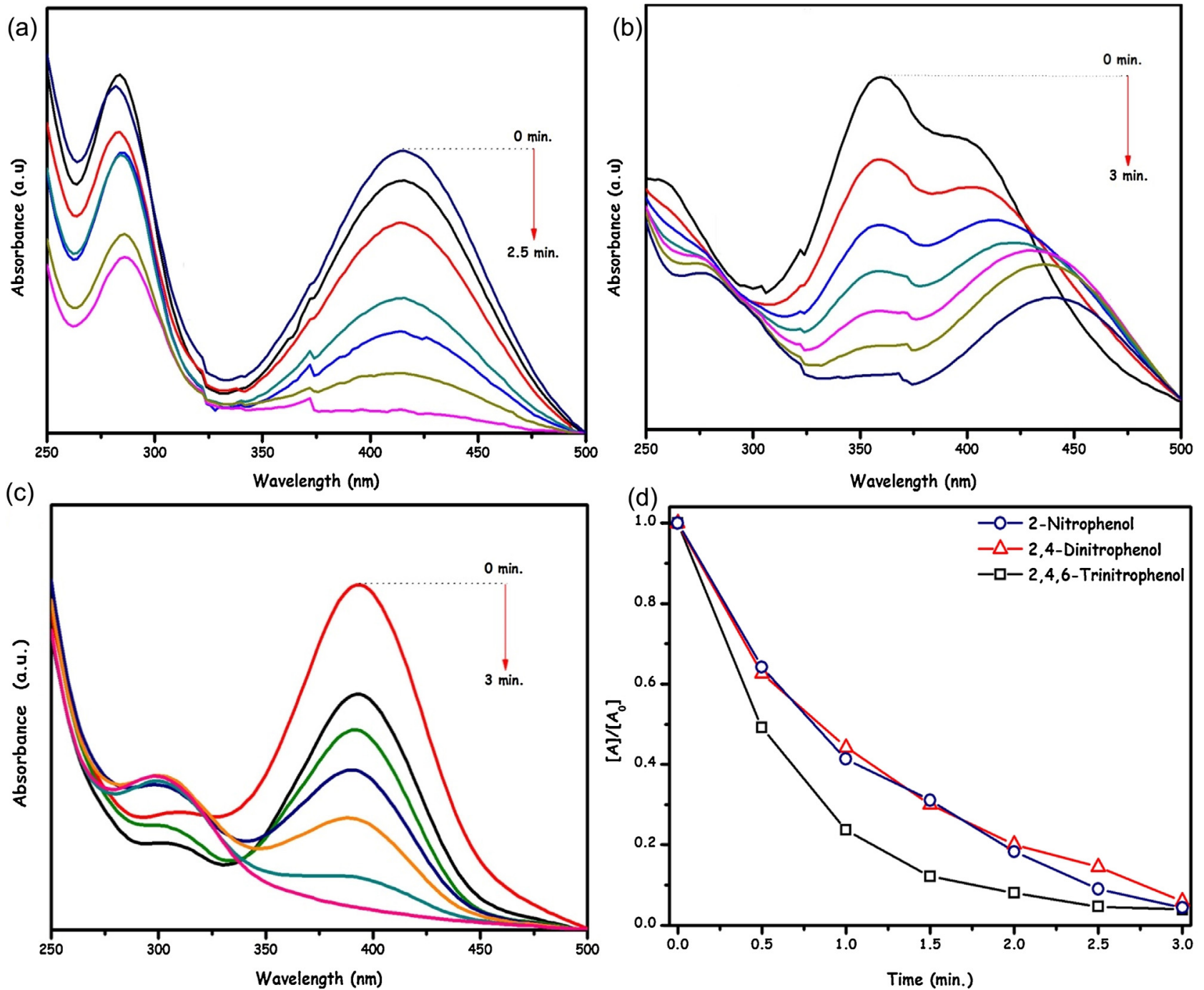

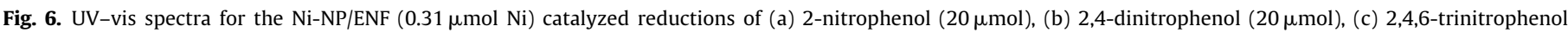

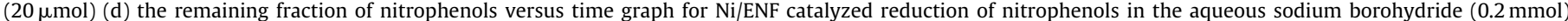
solution at room temperature under air.

Table 3

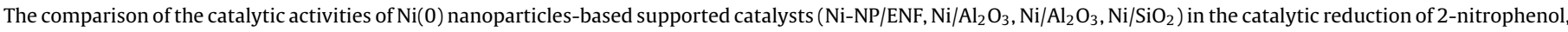
2,4-dinitrophenol and 2,4, 6-trinitrophenol in aqueous $\mathrm{NaBH}_{4}$ solution at room temperature under air.

\begin{tabular}{|c|c|c|c|c|}
\hline Substrate & $\begin{array}{l}\text { Ni-NP/ENF TOF } \\
\left(\mathrm{min}^{-1}\right)\end{array}$ & $\begin{array}{l}\mathrm{Ni} / \mathrm{Al}_{2} \mathrm{O}_{3} \mathrm{TOF} \\
\left(\mathrm{min}^{-1}\right)\end{array}$ & $\mathrm{Ni} / \mathrm{C}$ TOF $\left(\mathrm{min}^{-1}\right)$ & $\begin{array}{l}\mathrm{Ni} / \mathrm{SiO}_{2} \mathrm{TOF} \\
\left(\mathrm{min}^{-1}\right)\end{array}$ \\
\hline 2-Nitrophenol & 46.2 & 2.4 & 7.6 & 7.0 \\
\hline 2,4-Dinitrophenol & 48.2 & 6.5 & 8.7 & 8.3 \\
\hline 2, 4, 6-Trinitrophenol & 65.6 & 3.1 & 3.2 & 6.3 \\
\hline
\end{tabular}

3.4. The catalytic durability and uniqueness of Ni-NP/ENF in the reduction of 2-nitrophenol, 2,4-dinitrophenol and

2,4,6-trinitrophenol in the presence of $\mathrm{NaBH}_{4}$

The isolability and reusability as crucial measures of catalytic durability were also tested for Ni-NP/ENF catalyst in the catalytic reduction of 2-nitrophenol, 2,4-dinitrophenol and 2,4,6trinitrophenol at $298 \mathrm{~K}$. For this purpose, after the complete reduction of nitrophenols, Ni-NP/ENF catalyst was isolated as black films, washed with water, dried and bottled under argon atmosphere. The isolated Ni-NP/ENF catalyst was weighed and redispersed in aqueous fresh nitrophenols solutions and yet an active in the catalytic reductions (Fig. 9). The initial TOF values provided by Ni-NP/ENF catalyst at the $3 r$ reuse were calculated as $39.7 \mathrm{~mol}$ 2-nitrophenol/mol Ni min, $40.0 \mathrm{~mol}$ 2,4-dinitrophenol $/ \mathrm{mol} \mathrm{Ni} \mathrm{min}$, $54.0 \mathrm{~mol} 2,4,6$-trinitrophenol $/ \mathrm{mol} \mathrm{Nimin}$ at $298 \mathrm{~K}$. These results are revealing that $\mathrm{Ni}-\mathrm{NP} / \mathrm{ENF}$ catalyst retains 86,83 and $82 \%$ of its inherent activity even at 3 rd catalytic reuse in the reduction of 2-nitrophenol, 2,4-dinitrophenol and 2,4,6-trinitrophenol, respectively. The reusability performance of Ni/ENF catalyst is higher than that of obtained by $\mathrm{Au} @ \mathrm{SiO}_{2}$ [70], polygonal shaped $\mathrm{Au}$ [71] and citrate stabilized Au nanoparticles [72] used as catalyst in the reduction of nitrophenols.

The remarkable reusability performance of Ni-NP/ENF catalyst may be attributed to the high stability of the in-situ generated $\mathrm{Ni}$ NPs against to bulk Ni formation. Indeed, a representative BFTEM images of Ni/ENF sample harvested after the third reuse from the reduction of 2-nitrophenol still shows the existence of non- 

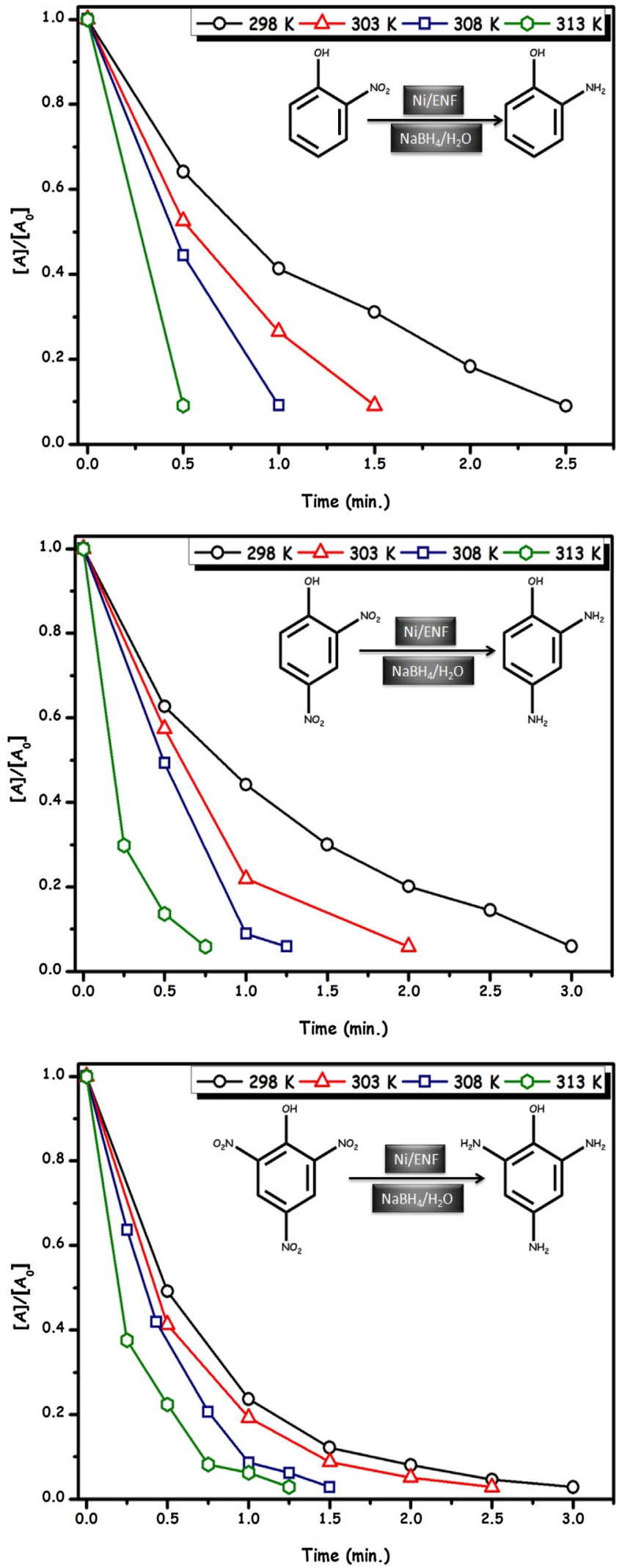

Fig. 7. The remaining fraction of nitrophenols versus time graph for Ni/ENF $(0.31 \mu \mathrm{mol} \mathrm{Ni})$ catalyzed reductions of 2-nitrophenol ( $20 \mu \mathrm{mol}), 2,4$-dinitrophenol $(20 \mu \mathrm{mol})$ and $2,4,6$-trinitrophenol $(20 \mu \mathrm{mol})$ in the aqueous sodium borohydride $(0.2 \mathrm{mmol})$ solution at different temperatures in the range of $298-313 \mathrm{~K}$.
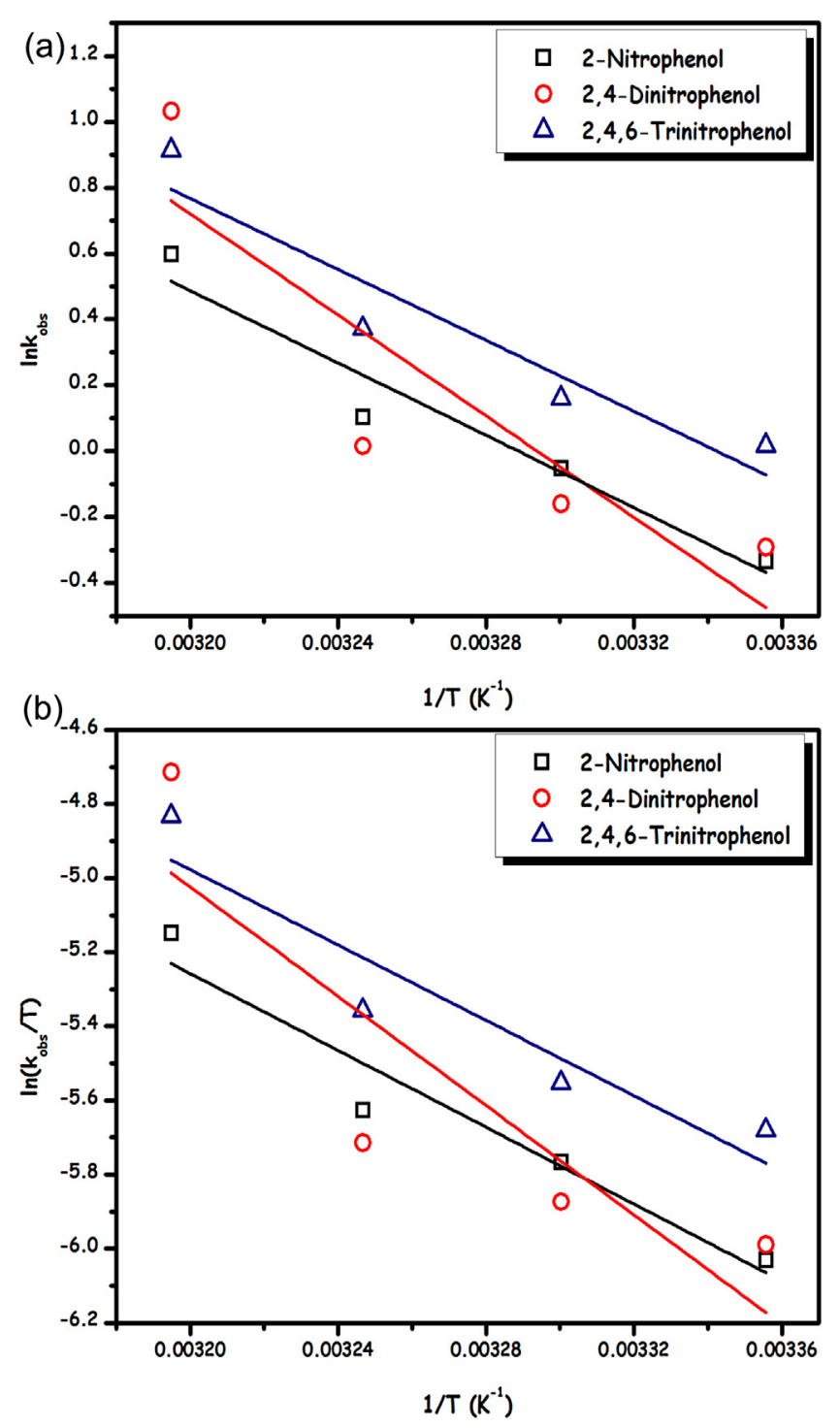

Fig. 8. (a) Arrhenius and (b) Eyring-Polonyi plots for Ni/ENF $(0.31 \mu \mathrm{mol} \mathrm{Ni})$ catalyzed reductions of 2-nitrophenol $(20 \mu \mathrm{mol}), 2,4$-dinitrophenol $(20 \mu \mathrm{mol})$ and $2,4,6$-trinitrophenol in the aqueous sodium borohydride $(0.2 \mathrm{mmol})$ solution.

agglomerated $\mathrm{Ni}(0) \mathrm{NPs}$ in Ni-NP/ENF catalyst (Fig. 10). The slight decrease $(\sim 15 \%)$ in the third catalytic reuse may be attributed to the decrease in the number of active surface atoms due to the clumping of surface supported $\mathrm{Ni}(0)$ nanoparticles, which were labelled in Fig. 10(c) and (d). More importantly, Ni was not detected in the filtrate collected from each cycle by the ICP-MS technique (with a detection limit of $28 \mathrm{ppb}$ for Ni) confirming that there is no indication of leaching of $\mathrm{Ni}(0)$ nanoparticles into reaction solution within the detection limit of ICP-MS.

\subsection{The catalytic uniqueness of Ni-NP/ENF in the reduction of 2-nitrophenol, 2,4-dinitrophenol and 2,4,6-trinitrophenol}

The uniqueness of $\mathbf{N i}$-NP/ENF was compared with the most commonly used solid support materials $\left(\mathrm{Al}_{2} \mathrm{O}_{3}, \mathrm{SiO}_{2}\right.$ and carbon). The catalytic activities of $\mathrm{Ni} / \mathrm{Al}_{2} \mathrm{O}_{3}$ (1.1\% wt Ni loading), $\mathrm{Ni} / \mathrm{SiO}_{2}(1.0 \% \mathrm{wt}$ $\mathrm{Ni}$ loading $)$ and $\mathrm{Ni} / \mathrm{C}(0.9 \% \mathrm{wt}$ Ni loading $)$ were tested in the reduction of 2-nitrophenol, 2,4-dinitrophenol and 2,4,6-trinitrophenol in the presence of equal amounts of $\mathrm{Ni}$ and $\mathrm{NaBH}_{4}$ at room temperature. The results of these experiments were given in Fig. 11, which indicates that the reduction of 2-nitrophenol, 2,4-dinitrophenol 

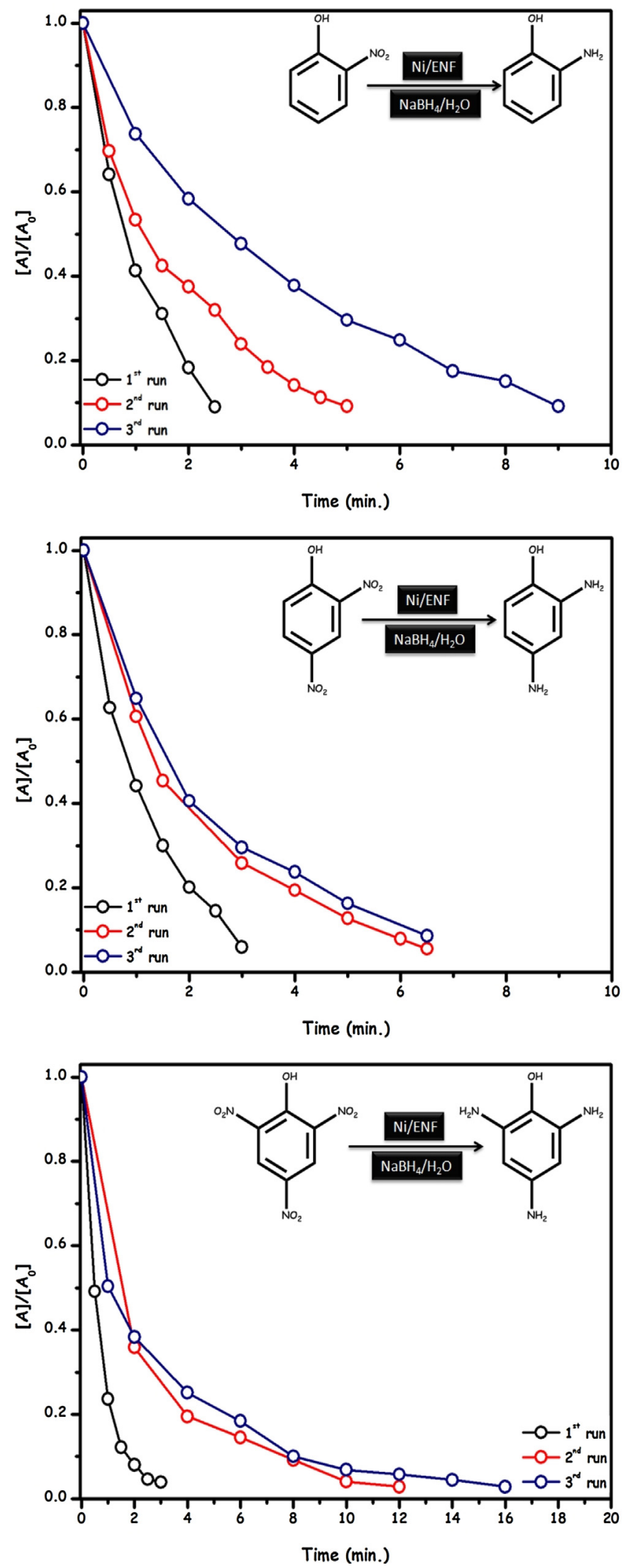

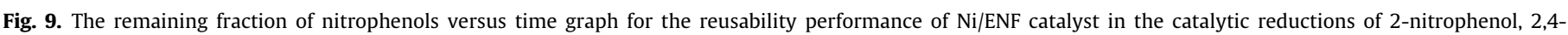
dinitrophenol and 2,4,6-trinitrophenol. 

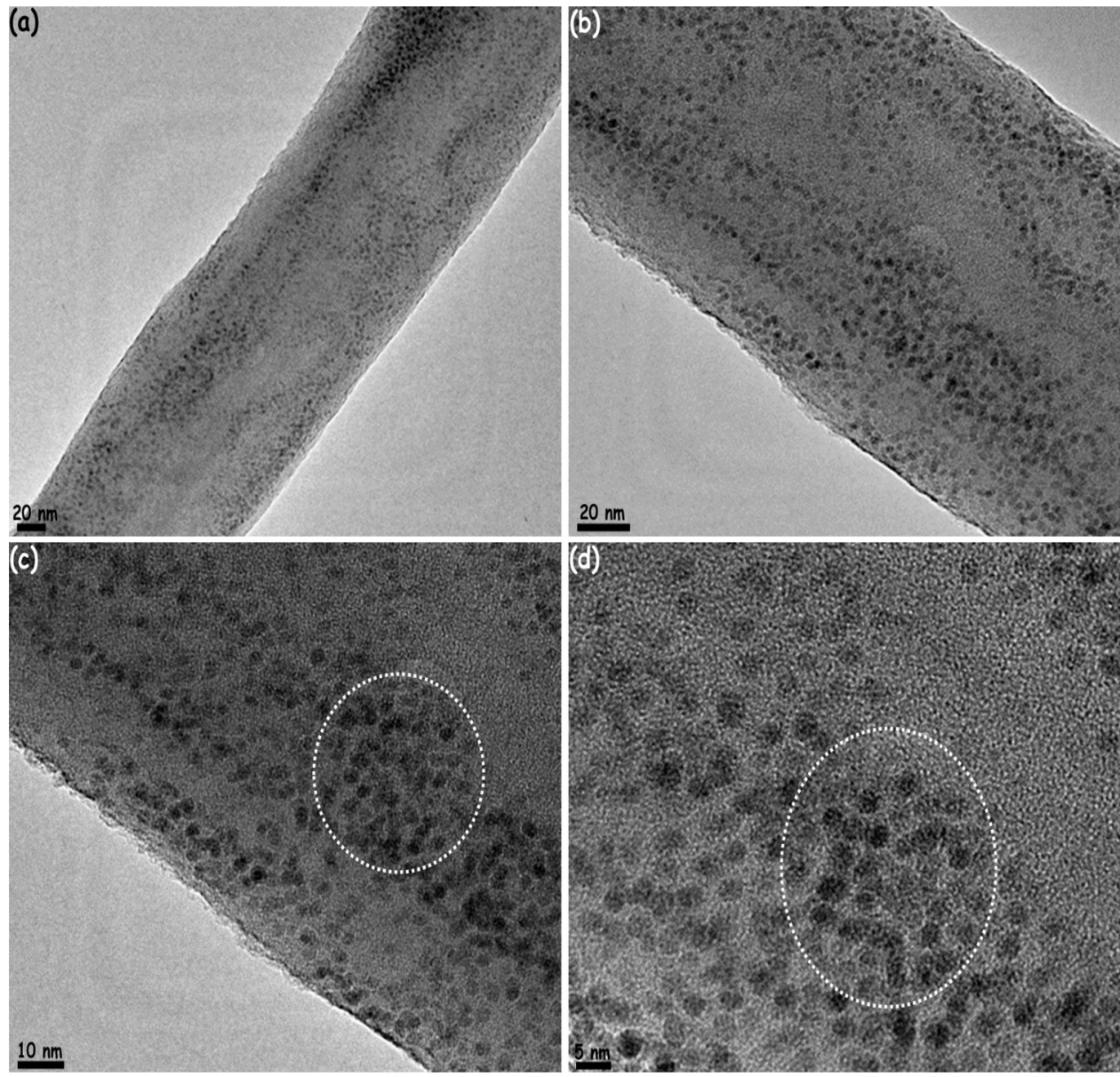

Fig. 10. BFTEM images (a-d) of Ni/ENF sample harvested after the third reuse from the reduction of 2-nitrophenol.

and 2,4,6-trinitrophenol proceeds more rapidly by Ni-NP/ENF catalyst. The initial TOF values of $\mathrm{Ni} / \mathrm{Al}_{2} \mathrm{O}_{3}, \mathrm{Ni} / \mathrm{SiO}_{2}$ and $\mathrm{Ni} / \mathrm{C}$ determined in the reduction of 2-nitrophenol, 2,4-dinitrophenol and 2,4,6trinitrophenol were compared with Ni-NP/ENF catalyst in Table 3. The comparison of these values shows that Ni-NP/ENF catalyst is at least 6 and at highest 20 times more active than nickel based $\mathrm{Ni} / \mathrm{Al}_{2} \mathrm{O}_{3}, \mathrm{Ni} / \mathrm{SiO}_{2}$ and $\mathrm{Ni} / \mathrm{C}$ catalysts. BFTEM analyses of $\mathrm{Ni} / \mathrm{Al}_{2} \mathrm{O}_{3}$, $\mathrm{Ni} / \mathrm{SiO}_{2}$ and $\mathrm{Ni} / \mathrm{C}$ catalysts showed that formation of larger sized $\mathrm{Ni}(0)$ nanoparticles (Fig. S4 in the Supporting information) with respect to Ni-NP/ENF catalyst, which explains higher activity of $\mathrm{Ni}-\mathrm{NP} / \mathrm{ENF}$ catalysts than $\mathrm{Ni} / \mathrm{Al}_{2} \mathrm{O}_{3}, \mathrm{Ni} / \mathrm{SiO}_{2}$ and $\mathrm{Ni} / \mathrm{C}$ catalysts. Although, these catalytic materials were prepared by the same methodology under identical conditions, the formation of small sized Ni-NP on PCL/chitosan nanofibers can be explained by the existence of chitosan $-\mathrm{NH}_{2}$ group on the surface of nanofibers, which acts as ligand stabilizer to surface bound nickel $(0)$ nanoparticles $[73,74]$ and prevent their surface agglomeration in Ni-NP/ENF catalyst.

\section{Conclusions}

In the current study, PCL/chitosan nanofibers supported nickel(0) nanoparticles (Ni-NP/ENF) were prepared, characterized and used as nanocatalyst in the catalytic reduction of various nitrophenols in the presence of sodium borohydride as a reducing agent. Some of the major findings of this study can be summarized as follows: (a) Ni-NP/ENF catalyst can reproducibly be prepared by the conventional wet-impregnation of $\mathrm{Ni}(\mathrm{II})$ onto $\mathrm{PCL} /$ chitosan nanofibers and their borohydride reduction under in-situ conditions during the catalytic reduction of nitrophenols in aqueous solution all at room temperature,

(b) Ni-NP/ENF catalyst was characterized by using ICP-OES, P-XRD, XPS, BFTEM, BFTEM-EDX and HRTEM analyses. The results of these multi-pronged analyses reveal the formation of welldispersed and highly crystalline nickel( 0$)$ nanoparticles on the surface of PCL/chitosan nanofibers,

(c) The catalytic performance of Ni-NP/ENF in terms of activity and stability was tested in the catalytic reduction of 2-nitrophenol, 2,4-dinitrophenol and 2,4,6-trinitrophenol in aqueous sodium borohydride solution under mild conditions (at room temperature and under air). Ni-NP/ENF was found to be highly active nanocatalyst in these catalytic transformations. They provide exceptional turnover frequencies in the catalytic reduction of 2-nitrophenol $(46.2 \mathrm{~mol}$ 2-nitrophenol/mol Ni min), 2,4-dinitrophenol (48.2 mol 2,4dinitrophenol $/ \mathrm{mol} \mathrm{Ni} \mathrm{min}$ ) and 2,4,6-trinitrophenol (65.6 mol 2,4,6-trinitrophenol/mol $\mathrm{Ni} \mathrm{min}$ ), which are the highest TOF values among the heterogeneous catalysts tested in the catalytic reduction of these substrates,

(d) Moreover, these new nickel(0) nanoparticles show exceptional stability throughout the catalytic runs against leaching and sintering so that they retain $>82 \%$ of their activity even at the $3 \mathrm{rd}$ catalytic reuse. 

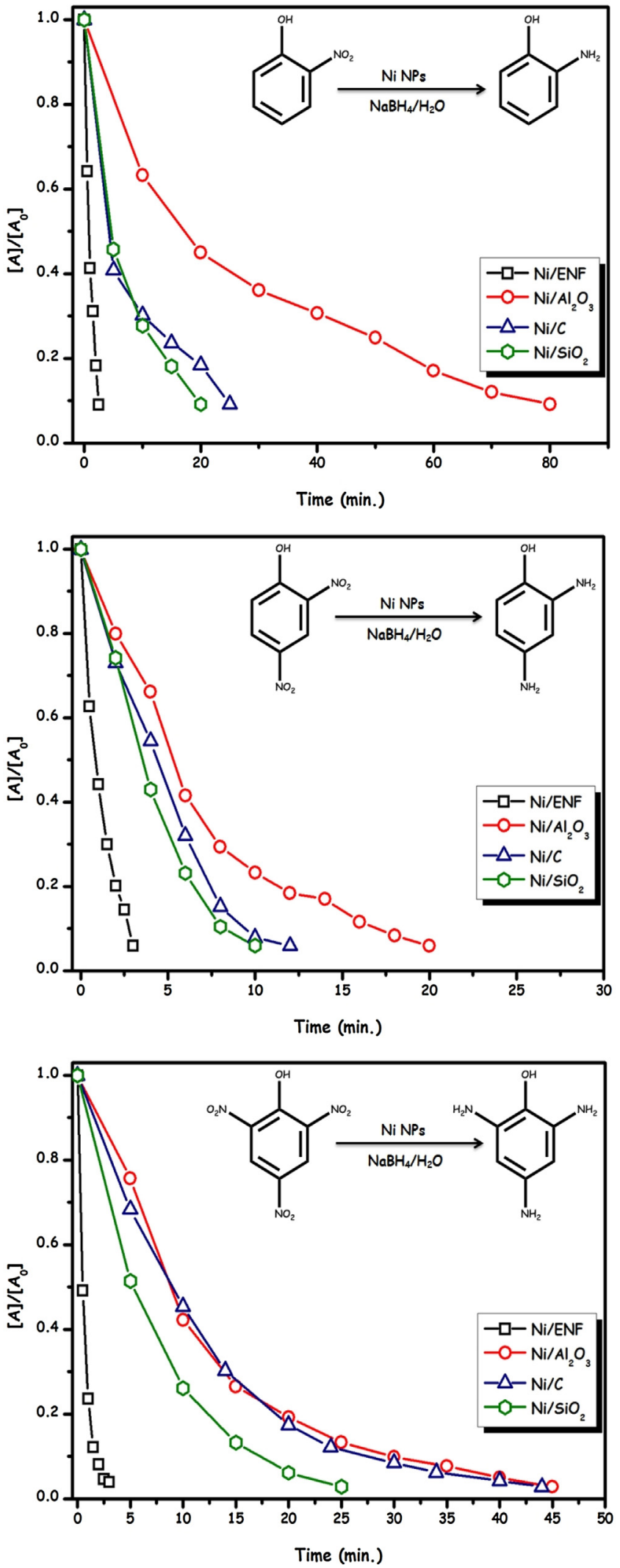

Fig. 11. The remaining fraction of nitrophenols versus time graph for Ni/ENF, $\mathrm{Ni} / \mathrm{Al}_{2} \mathrm{O}_{3}, \mathrm{Ni} / \mathrm{SiO}_{2}$ and $\mathrm{Ni} / \mathrm{C}$ (in all $0.31 \mu \mathrm{mol} \mathrm{Ni}$ ) catalyzed reductions of 2nitrophenol ( $20 \mu \mathrm{mol}), 2,4$-dinitrophenol $(20 \mu \mathrm{mol}), 2,4,6$-trinitrophenol ( $20 \mu \mathrm{mol})$ in the aqueous sodium borohydride $(0.2 \mathrm{mmol})$ solution at room temperature under air.
Overall, Ni-NP/ENF catalyst is available by a simple procedure and is found to be superior heterogeneous catalyst in terms of activity and stability in the catalytic reduction of 2-nitrophenol, 2,4-dinitrophenol and 2,4,6-trinitrophenol in aqueous sodium borohydride solution under mild conditions.

\section{Acknowledgements}

MZ thanks to the partial supports by Fevzi Akkaya Scientific Activities Support Fund (FABED), Science Academy and Turkish Academy of Sciences (TUBA). TU also thanks to The Turkish Academy of Sciences-Outstanding Young Scientists Award Program (TUBA-GEBIP) for partial funding.

\section{Appendix A. Supplementary data}

Supplementary data associated with this article can be found, in the online version, at http://dx.doi.org/10.1016/j.apcatb.2016. 10.020 .

\section{References}

[1] F.D. Marvin-Sikkema, J.A. Bont, Appl. Microbiol. Biotechnol. 42 (1994) 499.

[2] A.J. Crowe, P.J. Smith, J. Organomet. Chem. 224 (1982) 223.

[3] S.W. Ng, V.G. Kumar Das, J. Hole, Appl. Organomet. Chem. 11 (1997) 39.

[4] M. Gielen, A.M. Khloufi, M. Biesmans, Appl. Organomet. Chem. 7 (1993) 201.

[5] World Health Organization (WHO), 2012 Report Progress on Drinking Water and Sanitation, World Health Organization (WHO), 2012.

[6] T. Deblonde, C.C. Leguille, P. Hartemann, Int. J. Hyg. Environ. Health 214 (2011) 442.

[7] I. Ivancev-Tumbas, R. Hobby, B. Kuchle, S. Panglisch, R. Gimbel, Water Res. 42 (2008) 4117.

[8] M. Bielska, J. Szymanowski, J. Membr. Sci. 243 (2008) 273.

[9] O.A. O'Connor, L.Y. Young, Environ. Toxicol. Chem. 8 (1989) 853.

[10] A. Oren, P. Gurevich, M. Azachi, Y. Henis, Biodegradation 3 (1992) 387.

[11] M.S. Dieckmann, K.A. Gray, Water Res. 30 (1996) 1169.

[12] A. Di Paola, V. Augugliaro, L. Palmisano, G. Pantaleo, E. Savinov, J. Photochem. Photobiol. A: Chem. 155 (2003) 207.

[13] M.A. Oturan, J. Peiroten, P. Chartrin, Environ. Sci. Technol. 34 (2000) 3474.

[14] S. Yuan, M. Tian, Y. Cui, L. Lin, X. Lu, J. Hazard. Mater. 137 (2006) 573.

[15] N. Modirshahla, M.A. Behnajady, S. Mohammadi-Aghdam, J. Hazard. Mater. 154 (2008) 778.

[16] S. Kumar, S. Singh, V.C. Srivastava, Chem. Eng. J. 263 (2015) 135

[17] J.M. Cherm, Y.W. Chien, Water Res. 36 (2002) 647.

[18] S.B. Haderlein, R.P. Schwarzenbach, Environ. Sci. Technol. 27 (1993) 316

[19] P. Cañizares, C. Sáez, J. Lobato, M.A. Rodrigo, Ind. Eng. Chem. Res. 43 (2004) 1944.

[20] D.S. Silvester, A.J. Wain, L. Aldous, C. Hardacre, R.G. Compton, J. Electroanal. Chem. 596 (2006) 131.

[21] P. Zhao, X. Feng, D. Huang, G. Yang, D. Astruc, Coord. Chem. Rev. 287 (2015) 114.

[22] Y.C. Chang, D.H. Chen, J. Hazard. Mater. 165 (2009) 664.

[23] Y.T. Woo, D.Y. Lai, Aromatic Amino and Nitro-Amino Compounds and their Halogenated Derivatives Patty's Toxicology, Wiley, New York, 2001, pp. 1.

[24] S.C. Mitchell, R.H. Waring, Ullmann's Encyclopedia of Industrial Chemistry, Wiley-VCH, Weinheim, 2002.

[25] S. Panigrahi, S. Basu, S. Praharaj, S. Pande, S. Jana, A. Pal, S.K. Ghosh, T. Pal, J. Phys. Chem. C 111 (2007) 4596.

[26] J. Shwarz, C. Contescu, K. Putyera, Encyclopedia of Nanoscience and Nanotechnology, 2nd edition, Marcel-Dekker, New York, 2004.

[27] C.A. Mirkin, Small 1 (2005) 1.

[28] M. Zahmakıran, S. Özkar, Nanoscale 3 (2011) 3462.

[29] A. Doyle, S.K. Shaikhutdinov, S.D. Jackson, H.J. Freund, Angew. Chem. Int. Ed. 42 (2003) 5240.

[30] M. Poliakoff, J.M. Fitzpatrick, T.R. Farren, P.T. Anastas, Science 297 (2002) 807.

[31] N. Pradhan, A. Pal, T. Pal, Langmuir 17 (2001) 1800.

[32] K. Hayakawa, T. Yoshimura, K. Esumi, Langmuir 19 (2003) 5517.

[33] B. Baruah, G.J. Gabriel, M.J. Akbashev, M.E. Booher, Langmuir 29 (2013) 4225.

[34] F. Coccia, L. Tonucci, D. Bosco, M. Bressan, N. d'Alessandro, Green Chem. 14 (2012) 1073.

[35] J. Wang, X.-B. Zhang, Z.-L. Wang, L.-M. Wang, W. Xing, X. Liu, Nanoscale 4 (2012) 1549.

[36] M.L. Singla, A. Negi, V. Mahajan, K.C. Singh, D.V.S. Jain, Appl. Catal. A: Gen. 323 (2007) 51.

[37] J. Lee, J.C. Park, H. Song, Adv. Mater. 20 (2008) 1523.

[38] Z. Dong, X. Le, Y. Liu, C. Donga, J. Ma, J. Mater. Chem. A 2 (2014) 18775.

[39] X.-H. Li, X. Wang, M. Antonietti, Chem. Sci. 3 (2012) 2170.

[40] X. Lin, M. Wu, D. Wu, S. Kuga, T. Endo, Y. Huang, Green Chem. 13 (2011) 283 
[41] M. Zahmakıran, S. Özkar, Preparation of metal nanoparticles stabilized by the framework of porous materials, RSC Green Chem. Ser. (2010) 34, Chapter 3.

[42] H. Hou, D.H. Reneker, Adv. Mater. 16 (2004) 6.

[43] B. Kim, H. Park, S.H. Lee, W.M. Sigmund, Mater. Lett. 59 (2005) 829.

[44] D.H. Reneker, A.L. Yarin, Polymer 49 (2008) 2387.

[45] K. Yoon, B.S. Hsiao, B. Chu, J. Mater. Chem. 18 (2008) 5326

[46] S. Xiao, M. Shen, R. Guo, S. Wang, X. Shi, J. Phys. Chem. C 113 (2009) 18062

[47] X. Fang, H. Ma, S. Xiao, M. Shen, R. Guo, X. Cao, X. Shi, J. Mater. Chem. 21 (2011) 4493.

[48] Y. Huang, H. Ma, S. Wang, M. Shen, R. Guo, X. Cao, M. Zhu, X. Shi, ACS Appl. Mater. Interfaces 4 (2012) 3054.

[49] E. Formo, E. Lee, D. Campbell, Y. Xia, Nano Lett. 8 (2008) 668.

[50] P. Zhang, C. Shao, Z. Zhang, M. Zhang, J. Mu, Z. Guo, Y. Liu, Nanoscale 3 (2011) 3357.

[51] V. Thavasi, G. Singh, S. Ramakrishna, Energy Environ. Sci. 1 (2008) 205.

[52] M. Yurderi, A. Bulut, N. Caner, M. Çelebi, M. Kaya, M. Zahmakiran, Chem. Commun. 51 (2015) 11417.

[53] A. Bulut, M. Yurderi, Y. Karatas, Z. Say, H. Kivrak, M. Kaya, M. Gulcan, E. Ozensoy, M. Zahmakiran, ACS Catal. 5 (2015) 6099.

[54] Y. Karatas, A. Bulut, M. Yurderi, I.E. Ertas, O. Alal, M. Gulcan, M. Celebi, H. Kivrak, M. Kaya, M. Zahmakiran, Appl. Catal. B: Environ. 180 (2016) 586

[55] A. Bulut, M. Yurderi, Y. Karatas, M. Gulcan, H. Kivrak, M. Kaya, M. Zahmakiran, Appl. Catal. B: Environ. 164 (2015) 324.

[56] R.J. White, R. Luque, V.L. Budarin, J.H. Clarka, D.J. Macquarrie, Chem. Soc. Rev. 38 (2009) 481
[57] M.G. Yeo, G.H. Kim, Chem. Mater. 24 (2012) 903.

[58] G.H. Kim, H. Yoon, Appl. Phys. Lett. 93 (2008) 023127

[59] M. Zahmakiran, Mater. Sci. Eng. B 177 (2012) 606.

[60] M. Zahmakiran, S. Akbayrak, T. Kodaira, S. Özkar, Dalton Trans. 39 (2010) 7521.

[61] Z. Jiang, J. Xie, D. Jiang, X. Wei, M. Chen, CrystEngComm 15 (2013) 560.

[62] M. Zahmakiran, T. Ayvali, S. Akbayrak, S. Çalişkan, D. Çelik, S. Özkar, Catal. Today 170 (2011) 76.

[63] M. Yurderi, A. Bulut, M. Zahmakiran, M. Kaya, Appl. Catal. B: Environ. 160 (2014) 514.

[64] C. Wu, X. An, S. Gao, L. Su, RSC Adv, 5 (2015) 71259.

[65] S. Mondal, U. Rana, R.R. Bhattacharjee, S. Malik, RSC Adv. 4 (2014) 57282.

[66] N. Sahiner, H. Ozay, O. Ozay, N. Aktas, Appl. Catal. A: Gen. 385 (2010) 201.

[67] N. Sahiner, H. Ozay, O. Ozay, N. Aktas, Appl. Catal. B: Env. 101 (2010) 137.

[68] K.A. Connors, Theory of Chemical Kinetics, VCH Publishers, New York, 1990.

[69] M.V. Twigg, Mechanisms of Inorganic and Organometallic Reactions, Plenum Press, New York, 1994

[70] J.J. Li, J.C. Park, H. Song, Adv. Mater. 20 (2008) 1523.

[71] H. Rashid, T.K. Mandal, Adv. Funct. Mater. 18 (2008) 2261.

[72] F. Lin, H. Doong, J. Phys. Chem. C 115 (2011) 6591.

[73] M. Zahmakiran, M. Tristany, K. Philippot, K. Fajerwerg, S. Özkar, B. Chaudret, Chem. Commun. 46 (2010) 2938.

[74] M. Zahmakiran, K. Philippot, S. Özkar, B. Chaudret, Dalton Trans. 41 (2012) 590. 